Review Article

\title{
Energy Management Strategies for Smart Green MicroGrid Systems: A Systematic Literature Review
}

\author{
Chaimaa Essayeh $\mathbb{D D}^{1}{ }^{1}$ Mohammed Raiss El-Fenni ${ }^{1},{ }^{1}$ Hamza Dahmouni ${ }^{D},{ }^{1}$ \\ and Mohamed Aymane Ahajjam (iD) ${ }^{2}$ \\ ${ }^{1}$ Depatment of Communication Systems, INPT, Madinat Al Irfane, Rabat, Morocco \\ ${ }^{2}$ TICLab, International University of Rabat, Rabat, Morocco \\ Correspondence should be addressed to Chaimaa Essayeh; chaimaa.essayeh@gmail.com
}

Received 2 November 2020; Revised 16 January 2021; Accepted 31 January 2021; Published 25 February 2021

Academic Editor: Anna Diva Plasencia Lotufo

Copyright (c) 2021 Chaimaa Essayeh et al. This is an open access article distributed under the Creative Commons Attribution License, which permits unrestricted use, distribution, and reproduction in any medium, provided the original work is properly cited.

\begin{abstract}
Having neither precise definition nor a commonly accepted scope, the term "MicroGrid" tends to be used differently across researchers and practitioners alike. The management of energy usage within a microgrid is one of the topics that was handled from numerous perspectives. This study presents systematic literature review (SLR) of research on architectures and energy management techniques for microgrids, providing an aggregated up-to-date catalogue of solutions suggested by the scientific community. The SLR incorporated 45 papers selected according to inclusion/exclusion criteria and defined a priori. The selection process was based on an automated search and covered three known digital libraries. The extraction process covers three main questions. (i) The architectures of microgrids including their components, their bus configuration, and the adopted utility grid policy. (ii) The employed methods to ensure an optimal usage of energy under uncertainty. (iii) The confronted challenges and constraints of the suggested strategies. The findings of this SLR indicate a great diversity of methods and a rich background. Finally, the SLR suggests that future research should take into account the uncertainty aspect relating to energy management rather than the direct use of historical data as it is commonly done in most research papers. A sensitivity analysis should be provided in the latter case.
\end{abstract}

\section{Introduction}

The ever-increasing demand for electrical energy is a worldwide phenomenon which is the product of different changes happening across the nations. Coupled with a poor consumer awareness with regards to energy efficiency, the explosion in population growth and the wide spread and adoption of electronic devices in daily life are driving this trend to continue well beyond a couple of decades. This surge of demand imposes critical challenges facing grid utilities. Currently, the majority of electrical networks are relying on ageing infrastructures that restrict the performance of power delivery. As a result, the expansion of the grid proves to be complicated necessitating a radical transformation of the grid architecture and components. The installation of distributed generation units comes as an alternative solution to fill the continually expanding gap between demand and supply.

The use of distributed supply points presents many benefits especially in term of energy loss. In fact, the closer the generation to the consumer is, the less energy loss it undergoes. However, at the same time, this alternative solution faces some challenges. A distributed energy network will require its monitoring unit to migrate from the old-fashion centralized strategy presented by a unique monitoring unit to a new decentralized strategy. This implies more implication of computer technology and infrastructure. On the contrary, fossil fuels remain the dominant sources for both centralized and distributed power generation. Such sources of energy are exhaustible and are going to disappear in the short future. With the rise of new green technologies such as 
PV panels, wind turbines, and electrochemical batteries, new ways of generating and consuming energy emerge. It is considered that the integration of such clean distribution units can have many advantages to the electrical network. It can help mitigate climate change, alleviate load from the main utility grids, and avoid the blackout/ brownout.

"MicroGrid" ( $\mu$ grid) is flowering in the scientific community as the future of the electrical grid. Although it has neither well standardized definition nor defined scope, there is a common agreement that the $\mu$ grid is a smallscale energy network composed of loads and distributed energy resources. The integration of renewable energy resources (RER) puts more pressure on the monitoring units. In fact, the natural phenomena on which the RER rely are intermittent and the result is an unpredictable power supply. The fluctuations in the RER power output may cause network instability and yield to a demandsupply imbalance. Researchers suggested different methodologies to overcome these problems as well as to further advance green technologies incorporation. Particularly, managing energy within a $\mu$ grid has been studied widely using a variety of techniques in various contexts.

This paper provides a current state of the art regarding the application of energy management strategies in $\mu$ grids. The overview was performed following a defined methodology that is presented in Section 2. The results of the overview are divided into four parts and are presented in the remaining sections. The emphasize is first directed to the adopted architectures. We focus in this part on the common components that compose a $\mu$ grid, the different modes of its operation, the policy of connecting a $\mu$ grid to the main grid and the specifications associated with it, and finally the bus configurations that structure the connection of heterogeneous electric devices. In Section 3, we shed the light on the proposed methods presented in the research field to manage the energy usage in $\mu$ grids. Attention is then paid to various algorithms and simulation tools that are utilized to put into practice the suggested methods. As aforementioned, an efficient energy usage in $\mu$ grids faces many challenges and constraints. Those latter will be discussed in Section 5. The section that follows explains the limitation of our study and the difficulties that we encountered. Section 7 concludes the paper and opens on further suggestions.

\section{The Review Process}

The review process has been carried out, and the following steps are structured into three phases: planning, conducting, and documenting the review. Each phase involves several activities. In this section, we present how the review was planned and conducted. The planning phase includes the identification of the research questions and the development of the search process. Then, we proceed to the review conducting phase by selecting relevant studies and performing data extraction process.
TABLE 1: Search terms.

\begin{tabular}{lc}
\hline Facet & Search term \\
\hline \multirow{2}{*}{ Microgrid } & Microgrid \\
& Micro-grid \\
& Smart grid \\
& Smart building \\
Energy management & Energy balance \\
& Energy management \\
Optimization & Load balance \\
& Optimization \\
\hline
\end{tabular}

2.1. The Research Questions. The main objective of this study was to answer the following research question:

RQ: how do researchers and modellers tackle the problem of uncertainties of the RERs to ease their penetration in the future electrical grids?

The question was broken down into several "subquestions" that will help us focus on many facets of the implementation of $\mu$ grids.

RQ1: what are the suggested architectures of a $\mu$ grid? RQ2: what are the proposed methods for an efficient energy usage?

RQ3: what are the challenges faced and what constraints are commonly taken into consideration?

2.2. The Search Process. We searched the following three electronic databases:

(i) Elsevier Science Direct (http://www.sciencedirect. $\mathrm{com} /$ )

(ii) IEEEXplore (http://www.ieeexplore.ieee.org/Xplore/)

(iii) SpringerLink (http://www.springerlink.com/)

The search process was not evident to apply. The energy management in the $\mu$ grid could take many forms. For instance, the term "energy management" could not figure in the elements searched (title, abstract, ...) even if the paper tackles the subject. This could be load shifting, energy balance, state of charge management, energy scheduling, etc. Besides, for many studies, there is a mingling of the terms $\mu$ grid, smart grid, and smart building. We were obliged to enlarge our research target in order to include any relevant study. Table 1 lists the different synonyms, abbreviations, and alternative spellings of each of the individual facets of the study. The search terms of each facet were gathered using a Boolean "OR" operator, while the different facet items were combined using the Boolean "AND" operator.

A first selection based on the search strategy cited above turned out to be nonrelevant since a huge number of papers were returned. Thus, the search process was done in an iterative way, following the best practices of the agile methods. In fact, the search process has been updated throughout the review conducting phase as to ensure the selection of the most relevant papers. The aforementioned lack of standards and specifications regarding the management of $\mu$ grids has been very apparent during this study 
selection. For Science Direct library only, we found 604 papers based on our first search. We were obliged to narrow the scope of our search by applying a supplementary filter on papers. The filter selects only the papers in which one of these terms: PV, wind, solar, or "renewable energy" figures, since our interest is more oriented on how researchers tackle the problem of the intermittent aspect of RERs. Table 2 gives the final command that was used for the study selection in every database.

Table 3 reflects the number of papers found in each library after applying the search command, but before proceeding to the selection, thus providing a general idea about the papers published in the field of energy usage management for $\mu$ grids. With a growing yearly number of published papers in this topic, the research community's interest is apparent.

2.3. The Study Selection. We restrict our study to the first 15 relevant papers of each database. The papers selected for the study were subject to the following inclusion/exclusion criteria.

\section{Inclusion:}

(i) Only papers written in English were selected

(ii) The paper, be it a primary or secondary study, must propose an energy management strategy for green $\mu$ grids

Exclusion:

(i) Papers considering the whole smart grid network since our study is more lenient towards a userdriven low voltage networks.

(ii) Papers conducting research on the wireless micronetworks and communication.

(iii) Papers that focus on the communication facet of $\mu$ grids and optimize the communication energy among the network nodes.

(iv) Papers proposing energy forecasting techniques relating to RERs such as wind turbine and PV panels without proposing an energy management for $\mu$ grids.

(v) Papers not including a type of a RER since the focus of the study is on green $\mu$ grids.

(vi) Papers not including a type of energy storage. The models we are interested in include a type of energy storage that will increase the autonomy of the system be it working under an on-grid mode, off-grid mode, or hybrid mode.

(vii) Papers focusing on the charging/discharging scheduling of electric vehicles (EV) since their inclusion in $\mu$ grids is beyond the scope of our SLR.

2.4. The Data Extraction Process. After the selection was made, we proceed to processing the selected papers and extracting specific pieces of information that will help us answer the defined research questions: (i) The components of the $\mu$ grid, namely, the exploited RER, the storage, and the bus configuration

(ii) The operational mode of the $\mu$ grid, namely, on, off, and on/off modes

(iii) The adopted pricing model of the utility for the gridconnected and the switched mode $\mu$ grids

(iv) The adopted policy of energy flow with the main grid when dealing with grid-connected and switched modes

(v) The developed methods to overcome the problem of uncertainty and make an optimal usage of energy

(vi) The challenges and the constraints of the suggested strategies

In the remaining sections, we cover the last phase of the SLR and answer the defined research questions.

\section{RQ1: Architectures}

In this section, we will focus on the electrical architectures proposed in the selected papers for $\mu$ grid systems. Table 4 summarizes the first part of the findings of the review. We will focus as a first step on the different components that make up a $\mu$ grid. Next, we will discuss the management of power flow between these components. Finally, we will differentiate between the various bus system configurations for green $\mu$ grids.

We note that an efficient operation of a $\mu$ grid depends not only on its electrical configuration but also on its communication architecture. In fact, the projection of a monitoring infrastructure onto the already existing power system is what made a $\mu$ grid an actuality.

3.1. Integration of RERs in $\mu$ Grids. RERs, also known as Renewable Energy Sources (RES) or nondispatchable sources, are the type of technologies that provide energy from renewable natural phenomena such as solar intensity, wind speed, waves, tides, and geothermal heat. They usually have low greenhouse gas emissions compared to their fossil fuels counter parts and thus are considered a prominent player in climate change mitigation. While some RERs are implemented in large-scale projects, others were found to be suitable for small-scale implementations such as $\mu$ grids. The most implemented RERs in $\mu$ grids are PV panels and wind turbines.

3.1.1. PV-Based Systems. Recently, there has been a dramatic fall of PV panels' prices in the market. Coupled with other advantageous aspects (e.g., high conversion efficiency, light weight, and possibility of installation in the most unconventional conditions), PV panels became the most popular type of renewable energy to be implemented in a $\mu$ grid scale.

Generally, PV panels installed on rooftops convert solar irradiance into electric energy. The paper [14] introduces a new idea of hybrid PV thermal systems (PVT) producing either thermal or electrical energy. The thermal energy production can be used for heating water or air and 
TABLE 2: Search commands.

\begin{tabular}{|c|c|}
\hline Database & Search command \\
\hline Science Direct & $\begin{array}{c}\text { Title, abstract, and keywords: (microgrid OR micro-grid OR "smart building" OR "smart grid") AND ("energy } \\
\text { management" OR “energy balance" OR "load balance") AND (optimal OR optimization) } \\
\text { Find articles with these terms: (PV OR wind OR solar OR "renewable energy") AND storage } \\
\text { Years: } 2015-2018\end{array}$ \\
\hline $\begin{array}{l}\text { IEEExplore and } \\
\text { SpringerLink }\end{array}$ & $\begin{array}{c}\text { (("Smart grid" OR microgrid OR micro-grid OR "smart building”) AND ("energy management" OR "energy } \\
\text { scheduling" OR "load balance" OR "energy balance") AND (optimal OR optimization) AND (PV OR wind OR } \\
\text { solar OR "renewable energy")) AND storage } \\
\text { Years: 2015-2018 }\end{array}$ \\
\hline
\end{tabular}

TABLE 3: Number of papers' result of the search command.

\begin{tabular}{lccccc}
\hline & 2015 & 2016 & 2017 & 2018 & Total \\
\hline ScienceDirect & 50 & 64 & 89 & 114 & 317 \\
IEEExpore & 865 & 1104 & 1336 & 5163 \\
SpringerLink & 159 & 170 & 271 & 423 & 1023 \\
Total & 1074 & 1338 & 1696 & 2395 & 6503 \\
\hline
\end{tabular}

supplying thermal energy for domestic use. This implementation increases the efficiency of the system since the process of providing thermal energy passes through one step conversion (i.e., conversion to thermal energy) instead of passing through a two-step conversion (i.e., conversion to electric energy and then to thermal energy), saving losses related to the conversion process. Authors in [4] exploited a new potential of PV systems and studied the PV installation on facades.

Different equations were used to calculate the PV power output. The equation below is given in $[1,9]$, incorporating all important parameters that impact the PV output such as the temperature and the solar radiation:

$$
P_{\mathrm{PV}}=P_{\mathrm{PV}}^{\mathrm{nom}} \times \frac{G}{G_{\mathrm{ref}}} \times\left[1+K \times\left(T_{\mathrm{amb}}+\left(\frac{\mathrm{NOCT}-20}{800} G\right)-T_{\mathrm{ref}}\right],\right.
$$

where (i) $P_{\mathrm{PV}}^{\text {nom }}$ : nominal power of $\mathrm{PV}$ at standard test conditions, (ii) $G$ : solar radiation $\left(\mathrm{W} / \mathrm{m}^{2}\right)$, (iii) $G_{\text {ref }}=1 \mathrm{~kW} / \mathrm{m}^{2}$ : reference solar radiation, (iii) $K$ : temperature coefficient of power, (iv) $T_{\mathrm{amb}}$ : ambient temperature, (v) $T_{\text {ref }}=25^{\circ} \mathrm{C}$ : reference temperature at standard conditions, and (vi) NOCT: nominal operation temperature.

Some papers (e.g., $[6,22])$ neglect the term $(($ NOCT $20) / 800) G$ ) to give a simpler equation. Other simplified expressions for the output can be found in $[6,7,32]$. A detailed expression is presented in [14]. These equations showcase the relationship between the output with manufacturing parameters (e.g., short-circuit current $I_{\mathrm{sc}}$, open-circuit voltage $V_{\text {oc }}$, the maximum points of voltage $V_{\text {mpp }}$, and current $I_{\text {mpp }}$ ) as well with weather parameters (i.e., temperature and irradiance).

3.1.2. WT-Based Systems. For relatively large $\mu$ grids, PV panels can be combined with wind sourced energy. This technology is very suitable for rural areas and isolated regions since it allows to compensate the lack of PV output in cloudy periods. The WT power output depends on the wind speed as

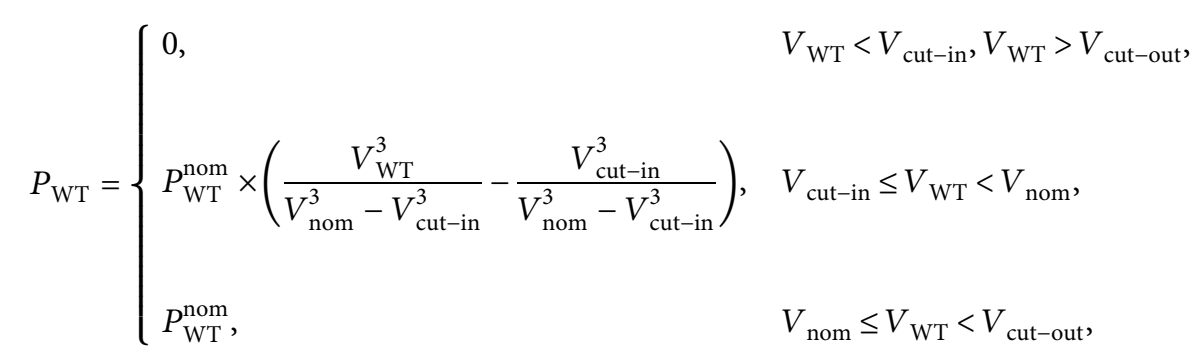

where (i) $V_{\mathrm{WT}}$ : wind speed, (ii) $V_{\text {nom }}$ : nominal wind speed, (iii) $P_{\mathrm{WT}}^{\text {nom }}$ : nominal power of the WT, (iv) $V_{\text {cut-in }}$ : cut-in wind speed, and (v) $V_{\text {cut-out }}$ : cut-out wind speed.

This equation is used in $[1,9,22,42]$. Other expressions, namely, equation (3), integrate power coefficients and air density and are given in $[11,32,36,43]$. A more detailed expression is presented in $[36,43]$ :

$$
P_{\mathrm{WT}}=\frac{\rho}{2} \times A \times C_{p}(\lambda, \beta) \times V_{\mathrm{WT}},
$$


TABLE 4: Suggested architectures.

\begin{tabular}{|c|c|c|c|c|c|c|c|}
\hline Ref & $\mathrm{ON} / \mathrm{OFF}$ & Utility pricing & RER & DER & Injection & ESS & Injection \\
\hline$[1]$ & OFF & - & PV WT & DG & - & BESS & - \\
\hline [2] & $\mathrm{ON}$ & Dynamic pricing & PV & - & $\mathrm{Y}$ & BESS & $\mathrm{Y}$ \\
\hline [3] & OFF & - & PV WT & - & - & BESS (lead-acid) & - \\
\hline [4] & $\mathrm{ON}$ & Dynamic pricing & PV & - & $\mathrm{Y}$ & BESS (Li-ion) & $\mathrm{Y}$ \\
\hline [5] & $\mathrm{ON} / \mathrm{OFF}$ & - & PV & DG & $\mathrm{Y}$ & BESS (lead-acid) & - \\
\hline [6] & OFF & - & PV & Fuel cell & - & BESS (Li-ion), hydrogen & - \\
\hline [7] & $\mathrm{ON}$ & TOU & PV & - & $\mathrm{Y}$ & BESS & $\mathrm{N}$ \\
\hline [8] & $\mathrm{ON}$ & Dynamic pricing & PV & - & $\mathrm{Y}$ & Ice storage & $\mathrm{N}$ \\
\hline [9] & OFF & - & PV WT & - & - & Pump ESS & - \\
\hline [10] & $\mathrm{ON}$ & & PV & - & $\mathrm{Y}$ & BESS & $\mathrm{Y}$ \\
\hline [11] & OFF & - & PV WT MHP & BMG & - & BESS & - \\
\hline [12] & OFF & - & PV & DG & - & BESS & - \\
\hline$[13]$ & OFF & - & PV & GT & - & BESS (lead-acid) & - \\
\hline [14] & $\mathrm{ON}$ & RTP & PV WT & MT FC & $\mathrm{Y}$ & BESS & $\mathrm{Y}$ \\
\hline [15] & $\mathrm{ON}$ & Flat & PV & $\mathrm{CHP}$ & $\mathrm{Y}$ & BESS (Li-ion), thermal storage & $\mathrm{N}$ \\
\hline [16] & $\mathrm{ON}$ & Dynamic pricing & PV WT & - & $\mathrm{Y}$ & BESS & $\mathrm{Y}$ \\
\hline [17] & $\mathrm{ON}$ & & PV WT & - & & BESS & \\
\hline [18] & $\mathrm{ON}$ & Dynamic pricing & PV WT & - & $\mathrm{N}$ & BESS & $\mathrm{N}$ \\
\hline [19] & $\mathrm{ON}$ & Quadratic & RER & - & $\mathrm{N}$ & ESS & $\mathrm{N}$ \\
\hline [20] & $\mathrm{ON}$ & Time-varying linear function & RER & - & $\mathrm{N}$ & ESS & $\mathrm{N}$ \\
\hline [21] & OFF & - & PV WT & DG MT & - & BESS (VRB), supercapacitor & - \\
\hline [22] & OFF & - & PV WT & DG & - & BESS (Li-ion) & - \\
\hline [23] & $\mathrm{ON}$ & TOU & PV & - & $\mathrm{N}$ & BESS (Li-ion) & $\mathrm{N}$ \\
\hline [24] & OFF & - & PV & - & - & BESS & - \\
\hline [25] & OFF & - & PV WT & DG & - & BESS, hydro-pumped storage & - \\
\hline [26] & $\mathrm{ON}$ & Dynamic pricing & PV WT & - & $\mathrm{N}$ & ESS & $\mathrm{N}$ \\
\hline [27] & $\mathrm{ON}$ & Dynamic pricing & PV & - & $\mathrm{Y}$ & BESS & $\mathrm{Y}$ \\
\hline [28] & ON/OFF & Dynamic pricing & PV WT & DG & $\mathrm{Y}$ & BESS & $\mathrm{Y}$ \\
\hline [29] & OFF & - & PV WT & MT & - & BESS & - \\
\hline$[30]$ & $\mathrm{ON} / \mathrm{OFF}$ & TOU & PV & - & $\mathrm{Y}$ & BESS & - \\
\hline [31] & $\mathrm{ON} / \mathrm{OFF}$ & Dynamic pricing & PV WT & DG & $\mathrm{Y}$ & BESS (VRB, Li-ion), supercapacitor & - \\
\hline [32] & $\mathrm{ON}$ & TOU & PV WT & DG, FC, MT & $\mathrm{Y}$ & BESS & $\mathrm{N}$ \\
\hline [33] & ON & - & PV WT & - & $\mathrm{N}$ & BESS & $\mathrm{N}$ \\
\hline [34] & ON & TOU & PV WT & - & $\mathrm{Y}$ & BESS (lead-acid) & $\mathrm{N}$ \\
\hline [35] & $\mathrm{ON}$ & Dynamic pricing & PV WT & - & & BESS & - \\
\hline [36] & OFF & - & PV WT & $\mathrm{FC}$ & - & BESS & - \\
\hline [37] & $\mathrm{ON}$ & Flat price & PV & - & $\mathrm{Y}$ & BESS & $\mathrm{N}$ \\
\hline [38] & $\mathrm{ON} / \mathrm{OFF}$ & Dynamic pricing & PV & DG & $\mathrm{Y}$ & BESS & $\mathrm{N}$ \\
\hline [39] & OFF & - & PV WT & DG & - & BESS (Li-ion) & - \\
\hline$[40]$ & $\mathrm{ON}$ & TOU & PV & MT, BMG & $\mathrm{Y}$ & BESS, thermal storage & - \\
\hline [41] & $\mathrm{ON}$ & RTP & PV WT & MT, FC & $\mathrm{Y}$ & BESS & - \\
\hline$[42]$ & $\mathrm{ON}$ & Auction price & PV WT & - & $\mathrm{Y}$ & Pumped storage & - \\
\hline [43] & OFF & - & PV & DG & - & BESS & - \\
\hline [44] & $\mathrm{ON}$ & TOU & RER & - & $\mathrm{Y}$ & ESS & $\mathrm{Y}$ \\
\hline [45] & $\mathrm{ON}$ & TOU & PV & - & $\mathrm{Y}$ & BESS (Li-ion) & $\mathrm{N}$ \\
\hline
\end{tabular}

where $\rho$ is the air density, $A$ is the swept area of the blade, and $C_{p}$ is the power coefficient that depends on the pitch angle $\beta$ and the tip speed ratio $\lambda$.

3.1.3. Micro-Hydropower System (MHP). A MHP system transforms the energy of flowing water into electrical energy. A turbine, a pump, or a waterwheel is used to convert the flowing power into rotational energy. The latter is then converted into electrical energy using a generator. The authors in [11] compute the power output of the MHP system using

$$
P_{\mathrm{MHP}}=\frac{9.8 \times H_{\mathrm{net}} \times \eta_{\mathrm{MHP}} \times \rho_{w} \times Z}{1000},
$$

where $H_{\text {net }}$ : net head, $\eta_{\mathrm{MHP}}$ : efficiency of the MHP system, $\rho_{w}$ : water density, and $Z$ : available discharge.

3.2. Conventional Energy Resources. The conventional energy resources or the dispatchable energy resources are small-scale energy generators relying on a specific type of fuel. Usually, they are used as a backup energy supply to overcome outage power events or as control sources to regulate frequency and voltage deviations. Common 
examples of conventional energy resources include natural gas turbines [13], microturbines [14], combustion turbines, biomass generators, and distributed generators.

3.2.1. Biomass Gasifier (BMG) System. The BMG systems are energy systems that rely on biomass as a fuel source to generate power or heat. Several biomass materials can be used, such as wood chips, animal waste, farm waste, and paper waste. Equation (5) from [11] calculates the power output of a BMG system:

$$
P_{\mathrm{BMG}}=\frac{\mathrm{Av} \times \mathrm{CV}_{\mathrm{BMG}} \times \eta_{\mathrm{BMG}} \times 1000}{365 \times 860 \times \mathrm{Op}} .
$$

where $\mathrm{Av}$ is the biomass availability (tons/year), $\mathrm{CV}_{\mathrm{BMG}}$ is the system's calorific value, $\eta_{\mathrm{BMG}}$ is the overall conversion efficiency from biomass to electricity, and Op is the operating hours per day.

The burning of biomass generates a significant amount of carbon dioxide, but it has less environmental impact than fossil fuels which is already included in the natural cycle of the biomass. BMG systems are then considered to be "cleaner" than the fossil fuel systems, but less "cleaner" than the RERs.

3.2.2. Distributed Generators (DGs). DGs convert the mechanical power into electric power. They consist of an engine that drives motors operating with gasoline, diesel [1, 27], natural gas, propane [39], etc. The most known DGs are diesel generators.

$P_{\mathrm{DG}}$, the output power of DGs in [22], is assumed to be proportional to the fuel consumption $\varrho_{\mathrm{DG}}$ with a coefficient of proportionality $a_{\mathrm{DG}}$ (i.e., fuel consumption coefficients):

$$
\varrho_{\mathrm{DG}}(t)=a_{\mathrm{DG}} P_{\mathrm{DG}}(t) \text {. }
$$

3.2.3. Fuel Cells. Fuel cells are another type of energy converters. These electrochemical cells transform the chemical energy of the fuel into electricity. There are five major types of fuel cells generally available in the market: alkaline fuel cell (AFC), phosphoric acid fuel cell (PAFC), molten carbonate fuel cell (MCFC), solid oxide fuel cell (SOFC), and proton exchange membrane fuel vell (PEMFC) [43].

In [1], the relation between $P_{\mathrm{FC}}$, the output power of FC, and $\varrho_{\mathrm{FC}}$, the consumption of fuel, is given by

$$
\varrho_{\mathrm{FC}}=a_{\mathrm{FC}} P_{\mathrm{FC}}+b_{\mathrm{FC}} P_{\mathrm{FC}}^{\mathrm{nom}},
$$

where $a_{\mathrm{FC}}$ and $b_{\mathrm{FC}}$ are coefficients of fuel consumption. A similar equation is given in [40]. A detailed formula for calculating the output voltage of a fuel cell is given in [36]. The expression includes among other parameters: the universal gas constant $(8.3145 \mathrm{~J} /(\mathrm{mol} \cdot \mathrm{K}))$, the Faraday constant (96485 A s/mol), the number of moving electrons, the charge transfer coefficient, the operating temperature $(\mathrm{K})$, the partial pressure of hydrogen inside the stack (atm), and the partial pressure of oxygen inside the stack (atm).
3.3. Energy Storage System (ESS) Integration. Electrical energy cannot be stored in the way it is generated. The ESSs are technologies that allow us to store another type of energy such as chemical energy or mechanical energy and convert it into electrical energy when needed. There is a large variety of ESSs in the market. These include electrochemical battery, super-capacitor, compressed air energy storage, and flywheel energy storage. When the $\mu$ grid is working as a standalone system, the main roles of an ESS are ensuring a continuous energy supply as well as stabling the DC bus voltage. When connected to the grid, the ESS (especially the battery) works in coordination with the other elements of the $\mu$ grid to meet its objectives as well be defined in Section 5.1.

The authors in [46] give a comprehensive overview of different ESSs and their roles when integrated in $\mu$ grids. Their technical roles and functions include the following: grid voltage and frequency support, grid angular (transient) stability, load levelling/peak shaving, spinning reserve, imbalanced load compensation, power quality, and reliability improvement.

There is a huge tendency in the $\mu$ grid research field that considers the battery of electric vehicles (EV) as an ESS and integrates it in the energy management policy; such systems can be the sole subject of another review. In fact, when an EV is present, its stored energy can be consumed in the system. Although, this can introduce additional constraints in the system (i.e., EV battery should be fully charged at some predefined periods).

3.3.1. Battery Energy Storage Systems (BESSs). Batteries are the common solution for energy storage in a $\mu$ grid scale. Their price is still not very affordable for household economy. Besides, the rigorous maintenance this type of ESS needs (e.g., requiring a dry and cool place and huge volume) does not encourage customers to adopt it as a solution. Still, it is the best choice compared with the aforementioned ESS solutions. When the type of battery is mentioned, it is either lead-acid or lithium-ion. The latter is getting more and more popular thanks to its high efficiency rate, its extended lifetime, and its deep depth of discharge (DoD).

The charging/discharging equation of a battery is as follows:

$$
\mathrm{SE}(t+\Delta t)=\mathrm{SE}(t) \times(1-\delta)+\left[\eta_{\mathrm{char}} \times \beta_{\mathrm{char}}-\frac{\beta_{\mathrm{dis}}}{\eta_{\mathrm{dis}}}\right] \times \Delta t
$$

With $\delta$ is the self-discharging rate, $\eta_{\text {char }}$ and $\eta_{\text {dis }}$ are, respectively, the charging and discharging efficiencies, $\beta_{\text {char }}$ and $\beta_{\text {dis }}$ are, respectively, the charging and discharging rates, and $\Delta t$ is the time step. Some assumptions could be made to simplify the equation:

(i) Neglect the self discharging rate (0.002)

(ii) Take $\Delta t$ equal to one hour

(iii) Take $\eta_{\text {char }}=\eta_{\text {dis }}$

(iv) Consider that the battery is either charging or discharging at a single time step 
This will lead to

$$
\mathrm{SE}(t+1)= \begin{cases}\mathrm{SE}(t)+\eta \times \beta_{\text {char }}, & \text { charging mode, } \\ \mathrm{SE}(t)-\frac{\beta_{\mathrm{dis}}}{\eta}, & \text { discharging mode. }\end{cases}
$$

3.3.2. Other ESSs. In [15], a thermal storage is used as a buffer storage. The authors in [9] used a pumped-storage plant under two operation modes: a pump mode and a discharge mode. They developed the water to power conversion equation and set the constraints related to the operation of the pump storage. In [8], the authors integrate an ice storage model for which the mathematical modelling is described in [47].

3.4. ON/OFF Modes of Operation. There are three types of $\mu$ grid operation: off-grid, on-grid, and on/off-grid. The offgrid mode, also known as stand-alone power system (SAPS), is an isolated mode or islanded mode. In this mode, the $\mu$ grid works autonomously without being connected to the utility grid. This mode of operation is very common in rural areas or in regions with harsh geographical conditions. The use of an ESS is very crucial since they store the energy during the period of peak production (i.e., when the generation exceeds the load demand, use it when the local generation becomes insufficient). A backup supply is also a plus in off-grid implementations since it will support the load in the worst case scenarios. Consequently, a precise design should be done to define the capacity of the local resources as well as the capacity of the ESS to ensure a good functioning of such systems and to avoid power outage.

When a $\mu$ grid is connected to the utility grid, we say that it is working under on-grid mode, connected mode, or gridtied mode. This mode is widely used in homes and businesses or any building located in zones supported by a utility grid company. The first version of this mode describes only DER with no ESS. Thus, any generated energy excess was exported to the grid for which the customer gets paid with a feed-in-tariff; any deficiency is supported by the utility grid. The significant drop in the price of ESS, especially batteries, encouraged their integration in such $\mu$ grids. This helps the $\mu$ grid to get the best of both worlds. The ESS is charged from the excess and discharged when needed. The utility acts as a backup supply providing the $\mu$ grid with energy when both generated and stored energy fail to fulfill the demand. With this type of operation, ESS is able to be charged from the utility during off-peak periods. The option of exporting the generated excess to the grid or charging the ESS from the grid will be further detailed in Section 3.5.

The last mode of operation is the on/off-grid mode. This mode is very similar to the on-grid mode with the only additional feature of being able to disconnect from the utility grid upon request. Generally, this type of $\mu$ grids works under an on-grid mode. When a fault occurs in the utility grid, the system switches to the off-grid mode in which it has to work autonomously and rely basically on the local resources. Similar to an off-grid $\mu$ grid, this system needs a good sizing to calculate the capacity of its components in order to ensure their operation under the partial autonomous mode. A basic layout scheme of the different modes of operation is shown in Figure 1.

3.5. Energy Exchange Policy with the Grid. The bidirectional flow of energy is only available for the on-grid or on/offgrid modes. From the 30 papers that suggested the on-grid mode, 22 papers used the bidirectional flow of energy as a valid option for the operation of the $\mu$ grid. Nevertheless, the possibility of exporting the local generated energy to the grid is not legally approved in many countries. In fact, the structure of the electrical grid that is currently implemented in almost all countries has a hierarchical aspect. At the highest level, we have the power plants where the energy is generated and transmitted to the high voltage (HV) stations, also called transmission networks; then, it passes through the medium voltage (MV) stations (or distribution networks) to the low voltage (LV) networks, from where it is delivered to consumers. As it is illustrated in Figure 2, the connection between different levels of power voltage is done via transformers. The traditional type of transformers has a limited performance preventing the bidirectional flow of energy, particularly from a lower to a higher level. Upgrading this equipment (and others) turns out to be very costly, and many utility companies around the world are not ready yet to take this step, as long as there is no incentive from the governmental institutions.Countries allowing the injection of energy into the public grid define a grid export limit. In Australia, for example, export is limited to $10 \mathrm{~kW}$. This limit is imposed to avoid signal disturbances occurring in transmission lines. The $\mu$ grid inverters must accurately respect the voltage and the frequency of the public grid, which are generally $240 \mathrm{~V}$ at $50 \mathrm{~Hz}$ or $120 \mathrm{~V}$ at $60 \mathrm{~Hz}$. Yet, from all the papers that allow the bidirectional flow of energy, only a few touched on the bound on the energy to be exported to the grid $[16,21,27,31,38]$. On the contrary, the export limit puts more constraint on the size of the $\mu$ grid system. Thus, the customer should make good decisions concerning the capacity of the implemented system in order to increase its return on investment and reduce the power waste.

The exchange of energy between the ESS and the utility grid is less common. Papers that allow the ESS to be charged from the utility grid are few; the ones that allow both charging and discharging from/to the grid are even fewer $[2,4,10,28]$. As a general case, the ESS is implemented to improve the reliability of the system and increase its autonomy. As a matter of fact, it is more common to see ESSs only charging from the excess of the local generated energy and discharging when needed by the customer.

3.5.1. Utility Pricing. The utility companies can adopt a static pricing or a dynamic pricing. In the former, the price is flat and does not change with time or demand. 

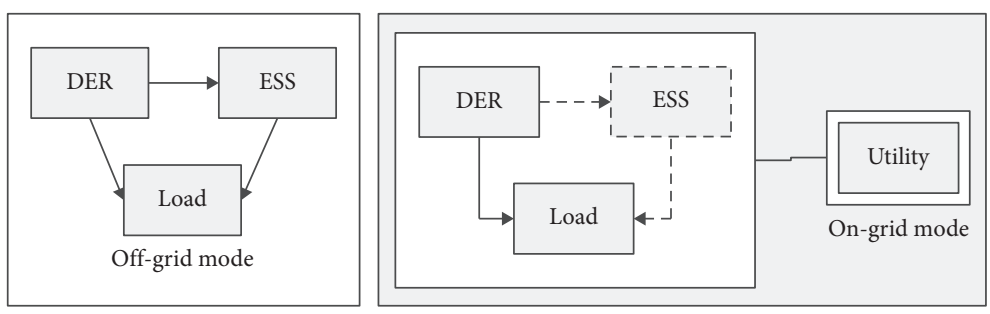

FIgURE 1: Modes of operation.

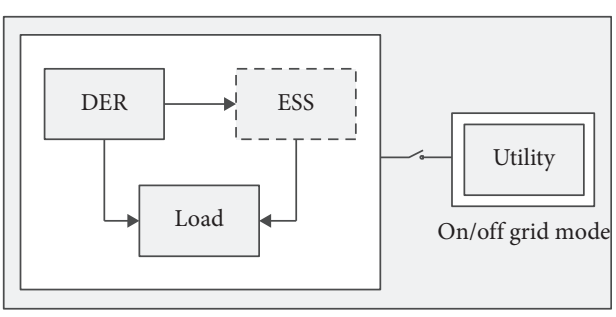

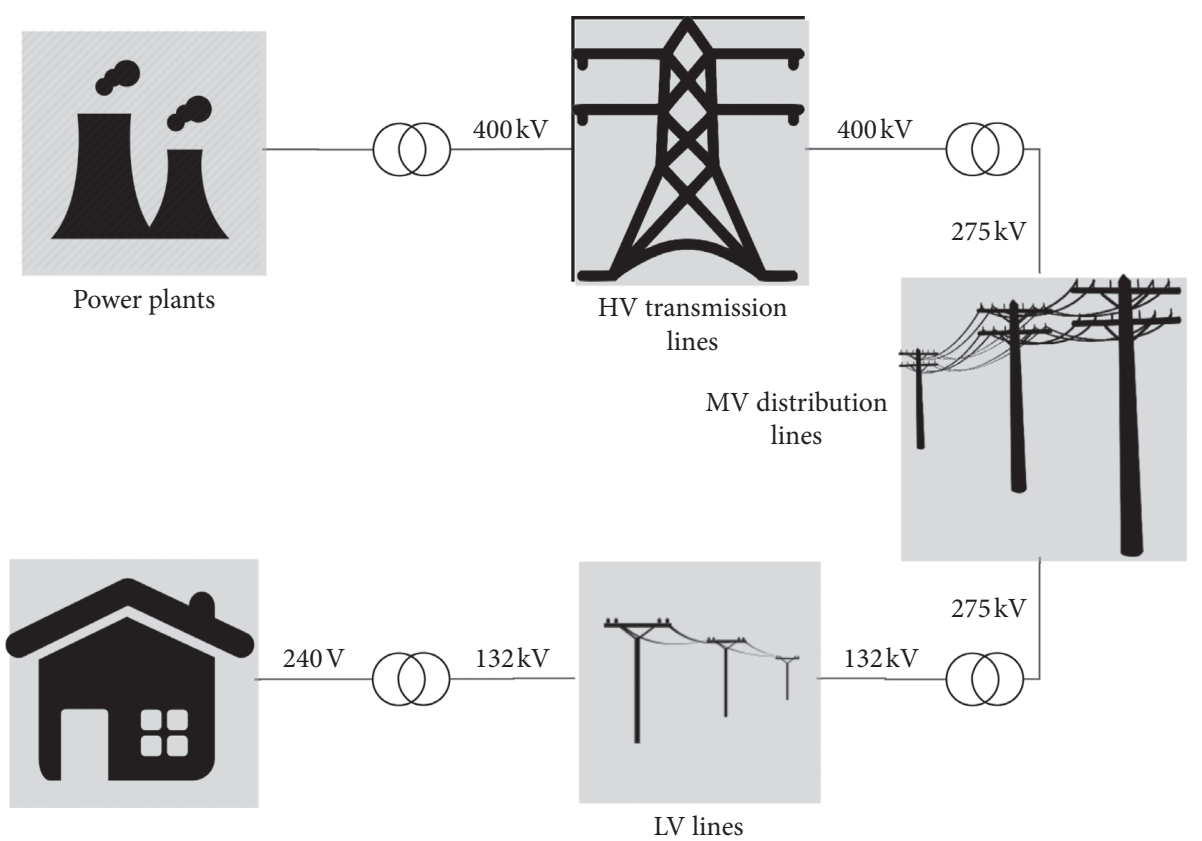

FIgURE 2: Example of a general structure of the public grid.

While in the latter, the price is not fixed and can change depending on several parameters such as the quantity of requested energy, the time of the day, and the period of the year. The static pricing is beneficial to neither the customer nor the supplier. In fact, during the peak periods (e.g., in early evening), the utilities are often obliged to activate "peak-plants" to catch up to the high demand of energy in this period. This type of plant is very costly and the solution proves to be inefficient. Therefore, to compensate the extra cost of activating the "peak plants," the company splits the cost evenly on the whole period of the day. And, this means that a customer who is running the washing machine or the dryer at $10 \mathrm{am}$ is then overpaying the cost of energy they consume. The idea of a dynamic pricing model to incentive customers is to shift/reduce their energy consumption from peak periods by rewarding them with lower prices for doing so.

Dynamic pricing models have been recently adopted by electricity companies not only for the benefits they provide but also because this was mandated by the governmental legislatures in some regions. Authors in [48] present an analysis of dynamic pricing in electricity grids and investigate the issues facing the integration of such pricing models in the energy market. They also listed the different existing models of dynamic pricing. Almost all the selected papers for this study stated that they have adopted a dynamic pricing for the energy drawn from the utility, but they do not provide the model used. When mentioned, the model of dynamic pricing is TOUP (Time-OF-Use Price) or RTP (Real Time Pricing). TOUP determines two or three levels of energy prices; each level for a certain period of the day. The price levels are predetermined and can be changed only once or twice a year (i.e., summer period TOUP and winter period TOUP). In RTP, instead of predetermining the price levels, the exact price value for each period is calculated and announced to the user only at the beginning of the trading slot.

3.5.2. Feed-in-Tariff (FiT). The FiT is the pricing policy created to promote investments in RERs. It is adopted by countries that encouraged the penetration of RERs in their power systems. The first FiT was introduced in the US during the late 1970s, and by the end of 2010, it has been enacted in 50 countries from which we cite Algeria, Germany, Iran, and Australia. The FiT provides a long-term agreement between the RER users and electricity companies and defines the price that the customer gets paid for injecting energy into the grid and the limit of quantity to be injected. 
3.6. Bus Configuration. RERs as well as batteries provide direct current (DC) energy. Most of the distributed generators supply alternating current (AC). The load is composed of both appliances that have to be fed by AC, such as washing machines and refrigerators, and others by DC, such as lighting and battery-powered devices. Therefore, many suggestions focusing on bus configuration for green $\mu$ grids exist in the literature.

The traditional method is the centralized DC bus configuration. It is very common especially in the implementation of isolated (off-grid) architectures. Figure 3 gives a general scheme of such configurations. The system is connected by a central DC bus to which the AC components are connected via AC/DC inverters. Several papers in the selection adapted this type of configuration, e.g., $[2,6,17,22,24,27]$. They justify their choice by stating that the DC configuration has more efficiency, less cost, less occupied space, lower lifetime cost, and high reliability [34]. Besides, implementing a DC configuration helps avoiding the frequency violation problem since only voltage stabilization is dealt with. However, this method presents several drawbacks. In fact, in a DC coupled system, the battery inverter is responsible for delivering the power. During the generated peak energy, the capacity of resources surpasses the capacity of the battery, resulting in a loss of the generated energy and limiting the performance of the system.

The centralized AC bus configuration shown in Figure 4 is a relatively more recent innovation. It provides an $\mathrm{AC}$ medium to govern the interactions between different components. The $\mathrm{DC}$ components are connected to the $\mathrm{AC}$ main bus through DC/AC converters or inverters. For example, in such configurations, the PV panels are connected to the AC bus through an AC inverter, and the batteries are either connected via a bidirectional converter or paralleled inverter and rectifier. The centralized AC configurations work under a higher operating voltage which results in fewer losses in wire cables. Moreover, unlike the DC configurations, the RERs can provide directly the power to home appliances. This enhances the expected lifetime of the battery by reducing its charge/discharge cycles and leads to a better exploitation of the RER. Nevertheless, this configuration requires additional safety measures (e.g., frequency stabilization) in addition to having a slightly higher installation cost than that of DC coupled systems. Compared to this latter, only fewer papers have adopted the AC configuration (i.e., $[16,21,25,43])$.

The last and the newest configuration is a hybrid DCAC coupling bus configuration (Cf. $[1,5,10,11,23,26]$ ). This bus configuration contains two main buses: an AC bus connecting the AC components and a DC bus connecting the DC components, as shown in Figure 5. The two buses are connected to each other via a bidirectional inverter. This configuration has the advantage of benefiting from both previous configurations. It necessitates minimum conversion requirements and reduced power converters, since every component is connected to either the DC or the AC bus, depending on its technical functioning, leading to a reduced system cost. Yet, such

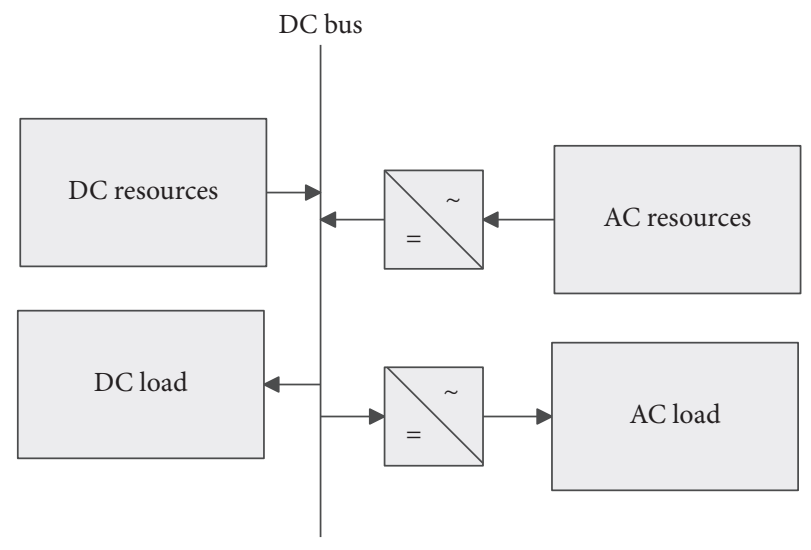

Figure 3: Centralized DC bus configuration.

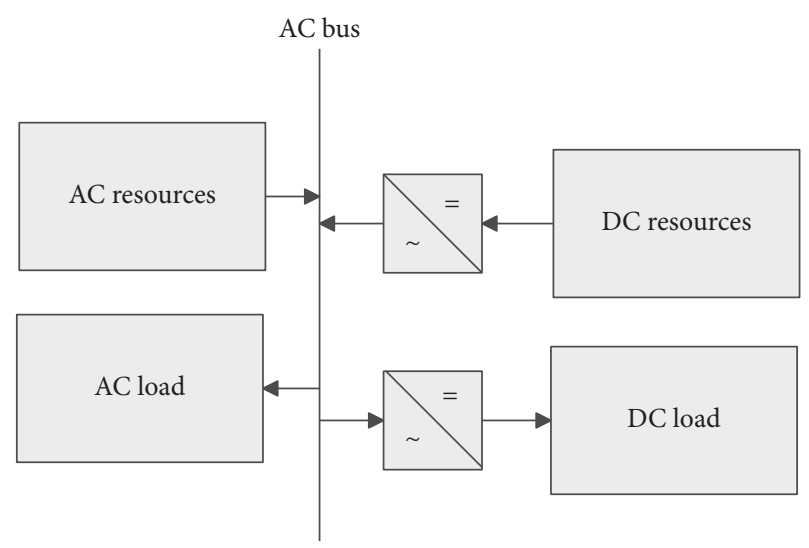

Figure 4: Centralized AC bus configuration.

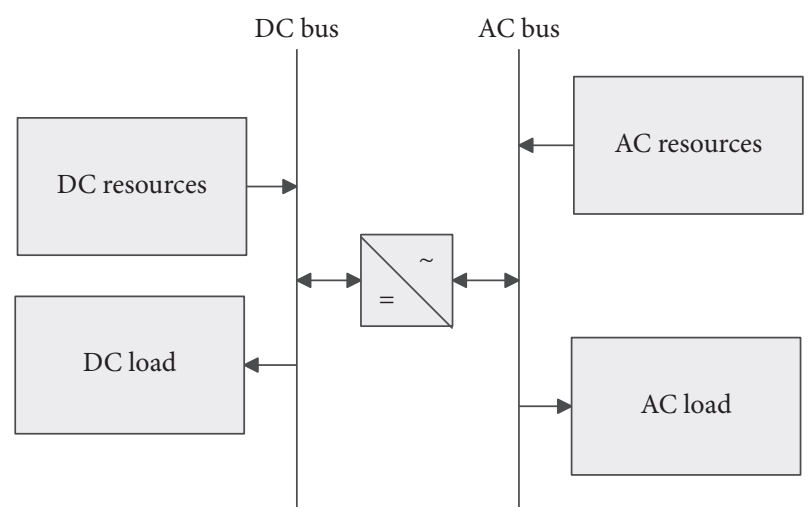

Figure 5: Hybrid AC/DC bus configuration.

configuration requires more coordination between DC and $\mathrm{AC}$ buses in terms of control strategy. In fact, coordinated bus voltage (and frequency) operations need to be considered.

In search of the most efficient configurations, many researchers conducted comparative studies of the different configurations. In [49], for instance, they deduced that hybrid AC/DC coupled systems offer some compelling advantages compared to other configurations. The system that underwent the study was composed of a genset, PV 
array, and a battery. Another study [50] concluded that the hybrid coupled AC/DC is beneficial in all the investigated scenarios.

\section{RQ2: Methods}

The major grid imbalances causing instability are frequency deviations, overloads, loss of synchronism, and voltage collapses [51]. As mentioned before, the system has to work with a $240 \mathrm{~V}$ at $50 \mathrm{~Hz}$ or with $120 \mathrm{~V}$ at $60 \mathrm{~Hz}$. Any deviation from the specified range of voltage/frequency operation will lead to system instability. The synchronism is lost when there is a phase shift in the signal angles, while overloads occur when there is an imbalance between the supply and the demand. Energy management strategies address the problem of overloads by ensuring a continuous energy balance within the system, while control strategies address the rest of the imbalances and propose some adjustment mechanisms to frequency and voltage.

The second part of the findings are listed in Table 5, outlining the different strategies employed in prior studies.

4.1. Control Strategies. It is challenging for systems integrating RERs to provide reliable and stable power to load demand. On the one hand, the intermittent characteristic of RERs may cause some fluctuations in the power they generate. On the other hand, RERs generate low power compared to the conventional sources. Control strategies (CS) aim to address these types of problems; their main role is to ensure a coordinated control of multiple sources and avoid network violations through controlling variables such as voltage, current, and frequency. The architecture (i.e., bus configuration and mode of operation) determines the tasks that should be handled by a CS. In fact, under a DC-bus configuration [17], only one component needs to be stabilized which is the DC power. In this case, the source providing a stable voltage output operates in a voltagecontrolled mode to regulate the DC bus voltage, while the other sources operate in the current-controlled mode. In the case of an AC-bus configuration, the adopted control scheme depends on whether the $\mu$ grid is isolated or gridconnected. In fact, if it was isolated, four components should be taken into account, namely, voltage, frequency, and active and reactive powers. Indeed, voltage and frequency are controlled through the $V / f$ control scheme that is implemented in the AC inverter to avoid related violations; while the other nodes operate under the PQ control scheme regulating the active and reactive powers. If the $\mu$ grid was connected to the main grid, this latter takes charge of voltage and frequency regulation. Thus, only two components are left to the $\mu$ grid to control which are active and reactive powers. They are implemented in nodes using either a PQ or a PV control scheme [52]. Flowchart in Figure 6 summarizes the different control schemes adopted by different $\mu$ grid configurations. We note that the most employed schemes are the PQ control scheme to regulate the active/reactive powers and the $V f$ control scheme to stabilize the voltage and frequency violations.
4.1.1. The V/f Control Scheme. The V/f control ensures that the output voltage is proportional to the nominal frequency. The voltage control maintains the nominal voltage amplitude by adjusting the reactive output of the $\mu$ grid. Similarly, the frequency control keeps the system working under the nominal frequency (e.g., $50 \mathrm{~Hz}$ ) by adjusting the active output of the system. The two equations of a $V / f$ control are shown below:

$$
\begin{aligned}
V_{i} & =V_{i}^{*}-m\left(Q_{i}-Q_{i}^{*}\right), \\
f_{i} & =f_{i}^{*}-n\left(P_{i}-P_{i}^{*}\right),
\end{aligned}
$$

where $V_{i}, f_{i}, P_{i}$, and $Q_{i}$ are the voltage amplitude, frequency, and active and reactive powers relative to the input electrical signal, while $V_{i}^{*}, f_{i}^{*}, P_{i}^{*}$ and $Q_{i}^{*}$ are their references. $m$ and $n$ are the drop amplitude and frequency coefficients.

4.1.2. PQ Control Scheme. The PQ control ensures that the active power $P$ and the reactive power $Q$ are regulated to remain fairly constant. In fact, when connected to the grid, voltage and frequency stability of an AC $\mu$ grid is handled by the main grid. While this keeps voltage amplitude and frequency varying within their allowable range, the PQ control scheme ensures that the active and reactive outputs remain unchanged. In addition of being implemented in connected $\mu$ grids, the PQ control scheme is also applied by slave nodes in the isolated mode.

The control technique widely used in the literature to implement control schemes is Pulse Width Modulation (PWM) technique, which can be implemented via a PI controller [10, 19, 52]. Authors in [52] give a comprehensive review on the application of different control strategies in both on- and off-grid modes of operation. To ensure $\mu$ grid stability, the control strategy is sometimes associated to a load management strategy, mainly a load shedding strategy. In $[24,43]$, for instance, the authors resorted to the latter strategy to keep voltage amplitude and frequency working under their predefined limits.

4.2. Energy Management Strategies. Energy strategy or energy management strategy is an umbrella term. It is widely known and used in utility companies and industrial settings. We can define the energy management strategy as the scheduling and the exploitation of different resources including RERs to handle the customer's demand load. Nevertheless, with the emergence of the $\mu$ grid concept, energy management started gaining interest in residential setting as well, and it was coined home energy management strategy (HEMS). From hereafter, we refer to this as EM strategy.

$\mu$ grid systems incorporate one or more types of RERs, which raises several challenges due to their stochastic nature. Therefore, the task of energy balance between production and consumption becomes less evident to achieve. To tackle these problems, researchers focus their efforts to find opportunities that save energy and reduce routine energy waste while keeping track of the system's unpredictability. 
TABLE 5: Energy management strategies.

\begin{tabular}{|c|c|c|c|c|c|}
\hline Ref & Method & Objectives & Constraints & Algorithm & $\begin{array}{l}\text { Simulation } \\
\text { tool }\end{array}$ \\
\hline$[1]$ & Sizing & Min COE, max reliability & RF, BESS constraints & MOSaDE & - \\
\hline [2] & EM & Min COE & $\begin{array}{l}\text { Thermal limit violation, voltage } \\
\text { stabilization, BESS constraints }\end{array}$ & $\mathrm{GA}+\mathrm{DSM}$ & $\begin{array}{l}\text { CEPLEX } \\
\text { Matlab }\end{array}$ \\
\hline [3] & Sizing & Min loss, max reliability & BESS constraints & Myopic & Matlab \\
\hline [4] & Sizing & Ensure balance & - & Myopic & $\begin{array}{l}\text { PVsys, } \\
\text { Crmsolar }\end{array}$ \\
\hline [5] & Sizing & $\begin{array}{l}\text { Min NPC, } \min \mathrm{COE}, \min \\
\mathrm{CO}_{2}\end{array}$ & $\mathrm{RF}$ & (GAMS) & HOMER \\
\hline [6] & EM & $\begin{array}{l}\text { Max reliability, min loss, } \max \\
\text { lifetime }\end{array}$ & $\begin{array}{l}\text { BESS, FC, hydrogen technical } \\
\text { constraints }\end{array}$ & $\mathrm{MPC}+\mathrm{DSM}$ & - \\
\hline [7] & EM & Min COE & BESS, utility technical constraints & MPC & - \\
\hline [8] & EM & Min peak demand & User comfort & Myopic + DSM & EnergyPlus \\
\hline [9] & EM & Min operation cost & $\begin{array}{l}\text { ESS, network and security constraints, } \\
\text { user comfort }\end{array}$ & GAMS & SBB solver \\
\hline$[10]$ & $\mathrm{CS}+\mathrm{EM}$ & - & BESS, utility technical constraints & Myopic & Matlab \\
\hline$[11]$ & EM & Min NPC & $\begin{array}{l}\text { Reliability, BESS and generation } \\
\text { constraints, excess of RER }\end{array}$ & Myopic + DSM & HOMER \\
\hline$[12]$ & EM & Min mismatch cost & BESS, generation and load constraints & Built algorithms & - \\
\hline$[13]$ & EM & $\begin{array}{l}\text { Min operation cost, max } \\
\text { reliability }\end{array}$ & BESS, generation and load constraints & MILP & SimplexLP \\
\hline$[14]$ & EM & Min operation cost & BESS and generation constraints & $\begin{array}{c}\text { Backtracking search optimization } \\
\text { algorithm (BSO) }\end{array}$ & - \\
\hline$[15]$ & EM & $\begin{array}{c}\text { Min operation cost, } \max \\
\text { reliability }\end{array}$ & ESS constraints & $\mathrm{MPC}+$ rule-based control & $\begin{array}{l}\text { Pyomo } \\
\text { (CPLEX) }\end{array}$ \\
\hline$[16]$ & EM & $\begin{array}{l}\text { Min cash flow, min } \mathrm{CO}_{2}, \max \\
\text { reliability }\end{array}$ & BESS and network constraints & Branch \& bound & Matlab \\
\hline$[17]$ & CS & Network stabilization & Voltage stabilization & $\begin{array}{l}\text { Time rate multiple pulse width } \\
\text { modulation (TRM-PWM) }\end{array}$ & $\begin{array}{l}\text { Matlab/ } \\
\text { Simulink }\end{array}$ \\
\hline$[18]$ & EM & Min COE & Energy balance & PSO & Matlab \\
\hline$[19]$ & EM & Min COE & ESS constraints & $\begin{array}{l}\text { Sliding-window-based sequential } \\
\text { optimization }\end{array}$ & - \\
\hline$[20]$ & EM & Min COE & ESS and network constraints & $\begin{array}{c}\text { Store-then-cooperate/cooperate- } \\
\text { then-store }\end{array}$ & - \\
\hline$[21]$ & EM & Min COE, max reliability & BESS and generation constraints & MPSO & $\begin{array}{l}\text { Matlab/ } \\
\text { Simulink }\end{array}$ \\
\hline$[22]$ & EM & Min NPC, max reliability & BESS and generation constraints & Myopic & Matlab \\
\hline$[23]$ & EM & $\begin{array}{l}\text { Min O\&M cost, max } \\
\text { reliability }\end{array}$ & BESS constraints & $\mathrm{PSO}$ & Matlab \\
\hline$[24]$ & CS & Voltage stabilization & BESS constraints & Myopic & $\begin{array}{l}\text { PSCAD/ } \\
\text { EMTDC }\end{array}$ \\
\hline$[25]$ & Sizing & Min annual cost, min $\mathrm{CO}_{2}$ & $\begin{array}{l}\text { BESS and generation constraints, } \\
\text { reliability }\end{array}$ & Branch \& cut & Matlab \\
\hline \multirow{2}{*}[26]{} & Sizing & $\begin{array}{l}\text { Min investment cost, min } \\
\text { expected operation cost }\end{array}$ & Budget & - & - \\
\hline & EM & Min operation cost & $\begin{array}{c}\text { BESS and load constrains, user } \\
\text { comfort }\end{array}$ & Built algorithm & - \\
\hline$[27]$ & EM & Min cash flow, max reliability & BESS constraints & Belleman dynamic programming & - \\
\hline$[28]$ & EM & Min operation cost & $\begin{array}{l}\text { BESS constraints, voltage stabilization, } \\
\text { user comfort }\end{array}$ & $\begin{array}{c}\text { Predictor corrector proximal } \\
\text { multiplier (PCPM) }\end{array}$ & - \\
\hline$[29]$ & EM & - & - & Auction theory & - \\
\hline$[30]$ & EM & Min COE & $\begin{array}{c}\text { BESS and generation constraints, } \\
\text { islanding constraint, peak shaving } \\
\text { constraint }\end{array}$ & Linear programming & $\begin{array}{l}\text { MAtlab } \\
\text { CPLEX }\end{array}$ \\
\hline$[31]$ & EM & Min COE & BESS and generation constraints & regPSO & - \\
\hline$[32]$ & EM & Min operation cost, min PAR & BESS constraints & Ant colony & - \\
\hline$[33]$ & EM & Min operation cost & BESS constraints & $\begin{array}{l}\text { Artificial neural network + linear } \\
\text { programming }\end{array}$ & Matlab \\
\hline$[34]$ & EM & $\begin{array}{l}\text { Min operation cost, min } \\
\text { emissions }\left(\mathrm{CO}_{2}, \mathrm{NO}_{x}, \mathrm{SO}_{2}\right)\end{array}$ & BESS and generation constraints & Fuzzy-logic & $\begin{array}{l}\text { Matlab/ } \\
\text { Simulink }\end{array}$ \\
\hline
\end{tabular}


TABle 5: Continued.

\begin{tabular}{|c|c|c|c|c|c|}
\hline Ref & Method & Objectives & Constraints & Algorithm & $\begin{array}{l}\text { Simulation } \\
\text { tool }\end{array}$ \\
\hline$[35]$ & EM & Min cost, min emissions & $\begin{array}{l}\text { BESS and generation constraints, user } \\
\text { comfort }\end{array}$ & Myopic + shedding & $\begin{array}{l}\text { Arduino/ } \\
\text { JADE }\end{array}$ \\
\hline$[36]$ & EM & Energy balance & BESS and generation constraints & Myopic + shedding & $\begin{array}{l}\text { Matlab/ } \\
\text { Simulink }\end{array}$ \\
\hline$[37]$ & EM & Min COE, min mismatch cost & $\begin{array}{c}\text { BESS, generation and load constraints, } \\
\text { user comfort }\end{array}$ & Myopic + shedding & Matlab \\
\hline$[38]$ & EM & $\begin{array}{l}\text { Min operation cost, min } \\
\text { mismatch cost, max profit }\end{array}$ & BESS, generation, network constraints & $\begin{array}{l}\text { Column-\&-constraint generation } \\
\text { algorithm (C\& CG) }\end{array}$ & $\begin{array}{c}\mathrm{C}++ \\
(\mathrm{CPLEX})\end{array}$ \\
\hline [39] & Sizing & Min lifetime cost & BESS constraints & Myopic & Matlab \\
\hline [39] & $\mathrm{EM}$ & Min operation cost & BESS, generation and load constraints & shedding + shifting & - \\
\hline$[40]$ & EM & Min COE & $\begin{array}{l}\text { Cooling/heating balances, electricity } \\
\text { balances operational constraints }\end{array}$ & Piecewise linear robust MILP & - \\
\hline$[41]$ & EM & $\begin{array}{l}\text { Min operation cost, min } \\
\text { emissions }\end{array}$ & BESS and generation constraints & MOPSO & Matlab \\
\hline$[42]$ & EM & Max profit & ESS and generation constraints & MILP & $\begin{array}{l}\text { GAMS } \\
\text { (CPLEX) }\end{array}$ \\
\hline$[43]$ & CS & $\begin{array}{l}\text { Min operation cost, min } \\
\text { mismatch cost }\end{array}$ & $\begin{array}{l}\text { BESS and generation constraints, } \\
\text { voltage and frequency stabilization }\end{array}$ & - & Matlab \\
\hline$[44]$ & EM & Min energy bill & User comfort & Built algorithms & JADE \\
\hline$[45]$ & EM & $\begin{array}{l}\text { Min operation cost, max } \\
\text { reliability }\end{array}$ & BESS and generation constraints & - & $\begin{array}{l}\text { GAMS } \\
\text { (CPLEX) }\end{array}$ \\
\hline
\end{tabular}

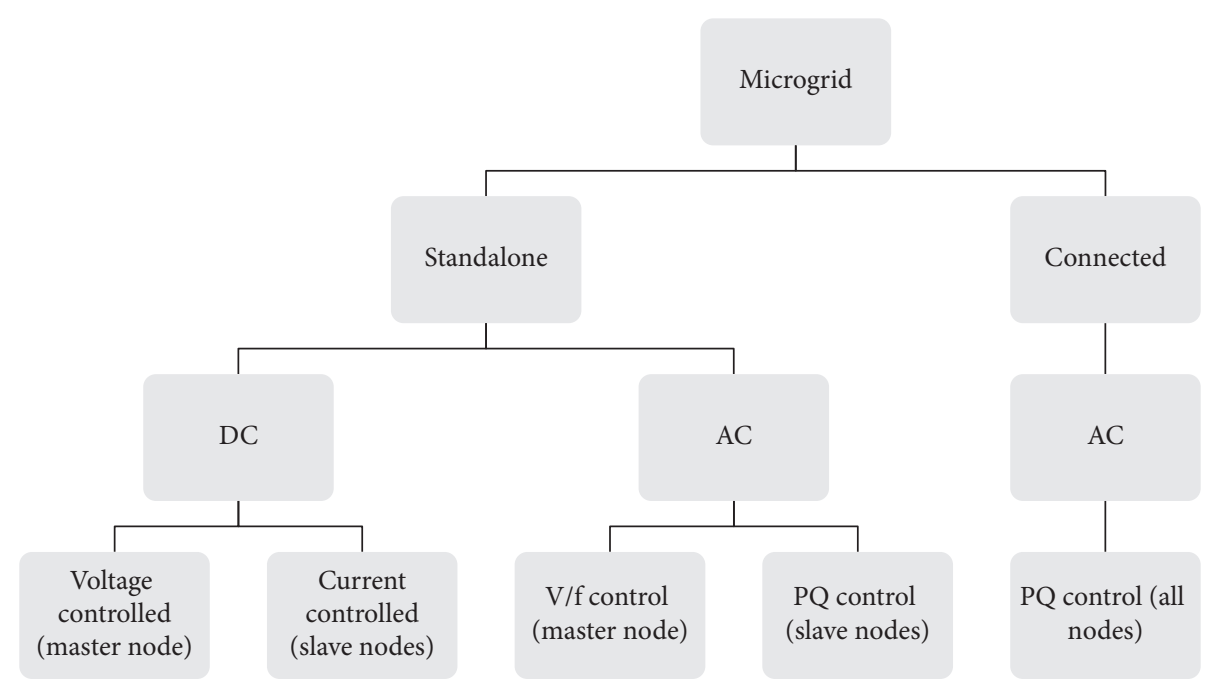

Figure 6: Summary of control schemes for microgrids.

The sizing (or design) of $\mu$ grids is the long term EM strategy that aims to reduce the investment cost of the implementation for the whole duration of the project. A short term EM, commonly on a daily basis, can be done subsequently to increase the opportunities of saving money and energy. These techniques include resources scheduling, load scheduling, or a combination of both. In the following sections, we provide more details of the different EM strategies cited above.

It is noteworthy that the EM strategies developed below are presented from a technical aspect only. Although as important, other aspects (e.g., behavioural aspects) are out of the scope of this paper. These later require more attention from the organizational structures to raise energy awareness among customers by encouraging them to replace inefficient equipments, install time switchers, and generally use less energy.

4.2.1. Design and Sizing. The optimal sizing is a technoeconomic approach conducted with the goal of finding the best scenario that will return the highest Return On Investment (ROI). From a customer perspective, questions such as what kind of DER technology best fulfil my needs? what should be the capacity of the implemented DER? what is the capacity of ESS that will increase the efficiency? and what if I increase the capacity of the DER, would it contribute to cost savings or would it be a waste of money because it would only generate unexploited energy excess? will need convincing answers. By performing an optimal 
sizing, we provide the customer with practical solutions for an optimal design of $\mu$ grids suitable for their needs and capacities.

The sizing implicitly includes an EM strategy. It is usually intuitive and based on a simple process also known in prior works as the myopic strategy. This strategy consists of giving a priority to the different energy resources in the system. This strategy starts by fulfilling the demand from the first energy supply priority. When this energy supply is not enough to feed the load, the system then activates the next energy supply priority and so on. Figure 7 shows a general example of such strategies involving three energy supplies: RER as a primary supply, ESS as a second supply, and the utility grid as the backup supply.More complicated strategies can be integrated in the optimal sizing for performing EM. For instance, the authors in $[13,26,34]$ performed a combined sizing and energy scheduling strategy. For a more detailed overview about the optimal sizing/design strategies for $\mu$ grids, see [53].

The most common cost to minimize is the net present cost (NPC). There are two types of constraints to take into consideration: financial constraints defined by the budget and technical constraints that include capacity limits, generation limits, and load limits.

4.2.2. Resource Scheduling. The supply/resource scheduling, also known as optimal power flow (OPF), involves the scheduling of the controllable generators and ESS. It gives the optimal dispatch of resources over a time horizon during which the scheduling is performed, as showcased in $[19,33]$. When the architecture contains only RER and ESS, the task is reduced to the optimal scheduling of charging/discharging of the ESS. The tools and algorithms the researchers used to perform the scheduling are detailed in Section 4.2.3. To tackle the problem of RER intermittency, the authors in $[23,34]$ combine a forecasting block with a scheduling strategy. The forecasting block predicts the weather data and the customer demand load.

4.2.3. Load Scheduling. Load scheduling is a part of the Demand Side Management (DSM)/Demand Response (DR) policies. It implicates load shifting, load shedding, and thermal load adjustment. Some papers consider the thermal load adjustment as a shifting technique. In fact, while the shifting impacts flexible (i.e, deferrable) loads for which the operation can be deferred over a specified period of time (i.e., washer-dryer and dishwasher), the thermal loads adjustment alters the power around the nominal power rating of power-level controlled appliances. Examples include heating, ventilation, and air conditioning systems (HVAC) and electric water heaters (EWH). For a short-term EM purpose, one or more of the aforementioned techniques can be combined.

(1) Load Shifting. Shifting appeared before the concept of smart grid. In fact, the industry has been the driving sector and the first one for which load shifting programs have been

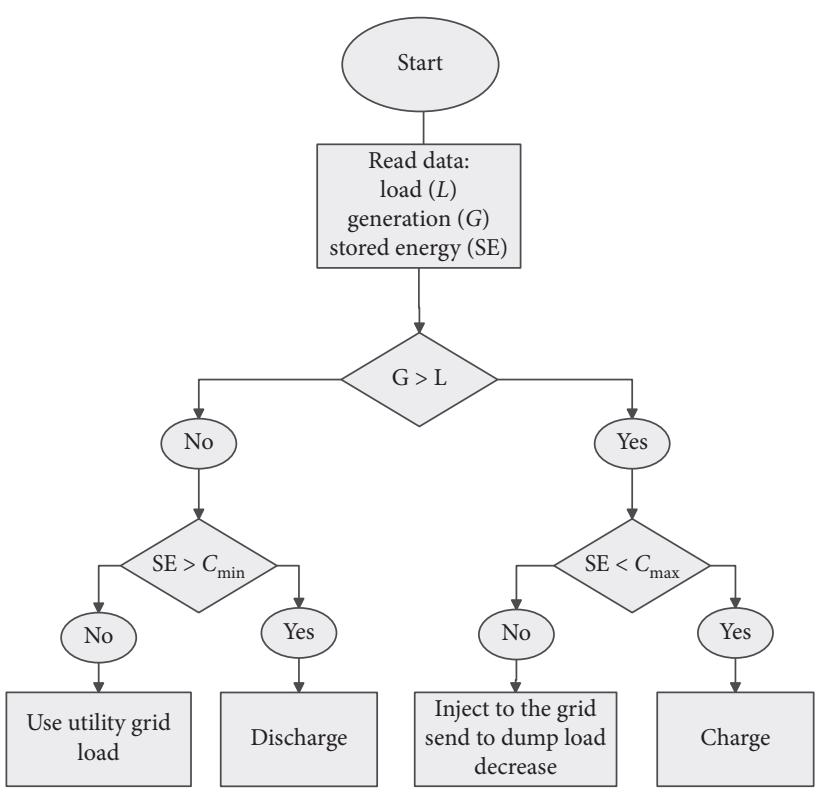

FIgURE 7: Example of myopic strategy.

deployed. Load shifting is a load rescheduling over time from on-peak hours to off-peak hours. The load rescheduling helps to reduce peak power to avoid overloads. The load shifting programs are always associated to an optimization of cost benefit, while respecting constraints such as customer preferences. The customer preferences are expressed via the classification of residential loads into different classes. The selected papers that used the shifting technique adopted various classifications, and we cite among others

(i) Permanent loads, priority loads, and shiftable loads: permanent loads refer to those that run for long periods of time such as refrigerators. Priority loads are those that are used regularly and can create discomfort in users if shifted/shed (e.g., EWH). Shiftable loads include washers [11].

(ii) Controllable (shiftable and elastic) and noncontrollable (nonshiftable and inelastic) loads: the latter refers to loads that cannot run on a scheduled date (e.g., electric cooker). Controllable loads on the other hand are divided into deferrable and powerlevel controlled loads. Deferrable loads have flexible starting-time operation (e.g., washing machine), while power-level controlled loads can vary their power around the nominal power of operation (e.g., water heater) [12, 27, 37].

(iii) Low, medium, and high priority loads: priorities are set according to customer preferences defining the order of which loads are fed with energy. The highest priority demands are satisfied at the beginning, then the medium priority demands, and finally the lowest priority ones [44].

We can set priority for shiftable loads in order to plan the operation of a load over another governed by a set of parameters such as the staring and ending time limits. 
(2) Load Shedding. Shedding is a traditional solution used to overcome the problem of overloads and network destabilization. The authors in [24] used it in their control strategy to keep the voltage network under a stable state. In $[33,35]$, loads were divided into critical and noncritical (i.e., ordinary) loads. In an event of overloads, the system starts dropping the noncritical loads starting with the least priority ones. In [36], loads were grouped into three categories based on their priority: $L_{1}, L_{2}$, and $L_{3}$. $L_{1}$ refers to loads that always have to be fed and $L_{3} / L_{2}$ to loads that are shed if an energy deficit occurs.

Combining shedding and shifting is also a common EM strategy. The authors in [8] perform a power shifting of HVAC and lighting and shed less priority loads. A classification of loads into interruptible and deferrable loads was performed in [28], where an interruptible load can be shed and a deferrable load can be shifted.

\subsection{Algorithms and Tools}

4.3.1. Algorithms. The two main approaches that are commonly used for EM in $\mu$ grids are rule-based approaches and optimization-based approaches. The former approaches follow a certain predefined criteria in order to make beneficial decisions for the system. They are mostly very simple with a low computational complexity but can provide efficient results. The myopic strategy, as it was demonstrated earlier in this paper, is an example strategy of this type of approaches. Papers using this method $[8,10,11,15,21,24,35-37]$ proved the effectiveness of such strategies through simulations. More advanced techniques can be incorporated with rule-based approaches for higher efficiency. We cite as examples artificial neural networks (ANN) [33], fuzzy logic [34], and the adoption of multiagent systems (MAS) [35-37, 44]. The use of the latter technique has garnered much interest lately. In fact, its incorporation helps to monitor the heterogeneous nodes (e.g., home devices, energy supplies, ESS, and communication nodes) composing a $\mu$ grid system by representing each node as an autonomous and intelligent agent capable of taking decisions to better achieve the common goal.

The latter approach (i.e., optimization-based) is more sophisticated. It derives from mathematical models and aims to optimize an objective function while taking into consideration environmental constraints. When it comes to optimizing the energy in the $\mu$ grid, it seems that heuristic algorithms and linear programming are the go-to tools.

Heuristic algorithms [54] are optimization algorithms that use the information currently gathered to help decide which candidate solution should be tested next or how the next individual can be produced. They are inspired form nature as they mimic the behaviour of living species. A variety of heuristics were used in the $\mu$ grid field. We cite multiobjective self-adaptive differential evolution algorithm (MOSaDE) [1], genetic algorithms (GA) [2], ant colony optimization (ACO) [32], backtracking search optimization algorithm (BSOA) [14], and particle swarm optimization (PSO) $[18,24]$ and $[21,31,41]$. The authors in the latter references used different versions of the same algorithm which are, respectively, modified PSO, regrouping $\mathrm{PSO}$, and multiobjective PSO. In all of the referenced papers, results were compared with other heuristic algorithms and found that the PSO always gives better results.

Linear programming (LP), also called linear optimization, is the maximization/minimization of an objective linear function subject to linear constraints. The general form of a linear optimization is as follows:

$$
\begin{array}{ll}
\min & { }_{x} f(x), \max _{x} f(x), \\
\text { s.t. } & A x \geq b, \quad A x \leq b, \\
& C x=d, \quad C x=d,
\end{array}
$$

where $x$ is the variable, $f$ is the linear objective function, $A$ and $B$ the parameters of the inequality constraint, and $C$ and $D$ are the parameters of the equality constraint. The resolution of a linear programming system returns the sets of vector $x$ specifying the maximum/minimum value of the objective function. Many papers used linear programming to solve the energy usage optimization problem $[13,30,40,42]$.

4.3.2. Tools. Many tools are used for the simulation of an EMS. They can be grouped into three categories: tools for simulating the output of the different technologies, tools dedicated for sizing purposes, and solvers for rule-based or optimization approaches.

In the first category, we find WindSim. A tool based on computational fluid dynamics (CFD) for wind modelling. It returns several outputs, regarding the targeted terrain, the wind field, and the energy produced by the wind farms [3]. The authors in [4] simulated the PV system with the help of the software PVsyst for the annual yield and Crmsolar for the hourly simulations. To simulate the CS strategy suggested in [24], the authors used PSCAD/EMTDC which is a popular tool for this task (see [52]).

The second category covers numerous tools with HOMER (Hybrid Optimization Model for Electric Renewable) $[5,11]$ and MSDO (Matlab/Simulation Design Optimization) $[3,25,39]$ being the most employed tool. A detailed list of the available tools can be found in the optimal sizing review in [53].

Matlab is also used for optimization purposes. It integrates a CPLEX solver for solving LP systems. Other software solutions providing CPLEX such as General Algebraic Modelling System (GAMS) $[42,45]$ and C++ are also used. In addition, Matlab can also be used to solving heuristic algorithms $[2,18,21,41]$ and to designing MAS systems $[36,37]$. Other interesting tools for optimization are Pyomo that was used in [15]. Pymo is a python-based optimization tool for LP, nonlinear programming, and mixed integer LP (MILP). JADE (java agent development environment) is also used for the modelling of MAS systems [35, 44]. 


\section{RQ3: Challenges and Constraints}

5.1. Objectives. Three main objectives are targeted when performing a microgrid optimization: Cost reduction, local resources use increase, and $\mathrm{CO}_{2}$ emissions reduction.

5.1.1. Cost Reduction. Economic benefit is the major concern taken into account by modellers and researchers alike. Different sources of cost are considered: energy generation, energy consumption, in addition to NPC which includes Cost of Energy (COE), and others detailed bellow. The NPC is used for long-term optimization (i.e., sizing/design). It is usually mentioned in papers that use HOMER as a solver $[5,11]$. The NPC represents the project's lifetime cost and includes the capital cost, replacement cost, operation and maintenance $(\mathrm{O} \& \mathrm{M})$ costs, and fuel cost in case the architecture incorporates a conventional energy source:

$$
\mathrm{NPC}=\frac{C_{\text {ann,tot }}}{\mathrm{CRF}},
$$

where $C_{\text {ann,tot }}$ is the total annual cost and CRF is the capital recovery factor defined by

$$
\mathrm{CRF}=\frac{i(1+i)^{n}}{(1+i)^{n}-1}
$$

where $i$ : the annual real interest rate and $n$ : the project lifetime. More detailed mathematical expressions describing how capital and replacement costs were distributed evenly on the project's lifetime can be found in [11].

The COE is the average cost of the electrical energy generated by the $\mu$ grid in $\$ / \mathrm{kWh}$. It can be used for short- or long-term optimization. It is computed in [1] by

$$
\mathrm{COE}=\frac{\mathrm{NPC}}{E_{\text {served }}} \times \mathrm{CRF}=\frac{C_{\text {ann,tot }}}{E_{\text {served }}} .
$$

Other costs were introduced in the papers such as the cost of generated energy $[15,23,28,38,41]$, the cost of degradation of ESS [38], the cost of purchased energy from the grid $[2,14,15,19,23,28,33,37,38,41]$, the start-up/ shut-down cost of DER [14,38,41], cost of fuel [13, 14, 43], and the comfort cost.

The comfort cost is the cost related to the nonsupplied energy [9] or to the action of shifting/shedding appliances $[38,43]$. In [26], for instance, the authors introduce a discomfort cost that measures the user experience under a load scheduling $x$ which deviates from their preferred power consumption $y$. It was called the mismatch cost in [12], and it penalized the change in the satisfaction of a user which was assumed to be proportional to the priority of the curtailed appliance. The same concept of cost was reproduced in [37] and was called the user drop. Lifetime was also included as a type of cost in [6], and it aims to increase the lifetime of devices by maximizing the state of health $(\mathrm{SoH})$ of different components.

When a paper mentions an operation cost, it may refer to one or a combination of the costs listed above. In [40], for instance, the cost includes the cost of interacting with the grid, the ageing cost of the battery, the gas cost, and the O\&M costs of RER. The losses are also expressed via a cost function. In [6], the authors took into consideration the cost of power lost during the conversion process (e.g., electrical conversion losses and chemical conversion losses).

5.1.2. Local Resources Use Increase/Reliability. The autonomy of $\mu$ grids is another concern for the scientific community. By increasing the use of local resources, we increase the autonomy of our system and implicitly attenuate the load from the main electric grid. In the studied papers, this metric has different mathematical expressions and is subject to minimization or maximization depending on the context.

(i) In [1], the authors minimize the power supply probability (LPSP) which is the probability of power supply failure to meet load demand.

(ii) In [3], the authors minimize the rate of nonsupplied demand load and the energy waste. The energy waste is the excess energy produced by RER which cannot be stored for ESS capacity limits.

(iii) In [6], the authors penalize the unmet demand load.

(iv) In [16], the authors maximize RER use as well as minimize utility grid use.

(v) In [45], the authors aim to have a zero purchased energy from the grid (i.e., zero-net energy consumption).

(vi) In [25], the authors take reliability as a constraint.

5.1.3. $\mathrm{CO}_{2}$ Emission Reduction. RER are pollutant-free; this is the main incentive to their incorporation in the electric grid. Any hybrid system that includes a non-RER would generate an amount of greenhouse emissions. Two interesting expressions were used in the selected studies. Equation (15) was used in [5], where $t_{\mathrm{CO}_{2}}$ presents the total amount of $\mathrm{CO}$ emissions, $m_{f}$ is the fuel quantity in litre, $\mathrm{HV}_{f}$ is the fuel heating value in $(\mathrm{MJ} / \mathrm{L}), \mathrm{CEF}_{f}$ is the carbon emission factor in (ton carbon/TJ), and $X_{c}$ is the oxidized carbon fraction. We note that $3.667 \mathrm{~g}$ of $\mathrm{CO}_{2}$ includes $1 \mathrm{~g}$ of carbon:

$$
t_{\mathrm{CO}_{2}}=3.667 \times m_{f} \times \mathrm{HV}_{f} \times \mathrm{CEF}_{f} \times X_{c} .
$$

In [25], the authors used another expression to penalize the $\mathrm{CO}_{2}$ emissions:

$$
C_{\mathrm{CO}_{2}}=\omega_{\mathrm{CO}_{2}} \times E=\omega_{\mathrm{CO}_{2}} \times \sum_{i} T_{\mathrm{DER}_{i}}\left[E_{\mathrm{DER}_{i}}^{\mathrm{op}} \varrho_{\mathrm{DER}}\right],
$$

where $\omega_{\mathrm{CO}_{2}}$ : weight assigned based on the $\mathrm{CO}_{2}$ cost European negotiation, $E_{\mathrm{DER}}^{\mathrm{op}}$ : the $\mathrm{CO}_{2}$ emissions generated by the operation of the unit $\mathrm{DER}_{i}, \varrho_{\mathrm{DER}_{i}}$ : fuel consumption at one unit of time, and $\mathrm{TDER}_{i}$ : the number of time units the unit $\mathrm{DER}_{i}$ was operating.

If the objective consists of increasing the use of RERs, it goes back to decreasing carbon emissions [13].

5.1.4. Lifetime. The authors in [6] introduced another metric, i.e., SoH. $X_{\text {nom }}(t)$ and $X_{\text {nom }}^{0}$ are, respectively, the actual nominal capacity (or power) and the initial nominal 
capacity (or power). When the component is new, $\mathrm{SoH}=1$; when it reaches 0 , the component is considered obsolete and must be replaced. This metric is governed by

$$
\operatorname{SoH}(t)=a \frac{X_{\text {nom }}(t)}{X_{\text {nom }}^{0}}-b,
$$

where $a>b$ and $a$ and $b$ are the coefficients that change depending on the component. $X$ can be capacity or power.

Other metrics for calculating battery ageing are also introduced in the same reference such as the calendar ageing $A_{\text {cal }}$ and the cycling ageing $A_{\text {cyc }}$.

An ESS's SoH is considered as an objective in some papers [6] and a constraint in others [16, 27], whereas, in [27], it was constrained by a minimum bound $\mathrm{SoH}_{\min }$.

5.2. Challenges. The intermittent aspect of RERs and the unpredictable behaviour of consumers are the main challenges faced with the implementation of RERs-based $\mu$ grids. To tackle this problem, researchers mainly base their techniques on historical data. Nevertheless, other advanced solutions are employed in the literature including probabilistic models, forecasting models, and stochastic optimization.

5.2.1. Historical Data. This method is adopted mainly for sizing since, at this stage, EM can be performed from a macroscopic perspective (i.e., no need for real-time data). Yet, other papers rely on it to assess the performance of their suggested EM strategy. Many papers have adopted this method to simulate their systems (e.g., $[1,3,17])$. For instance, the authors in [2] used their own historical data (i.e., load profiles and PV output) for the proposed EM strategy. The authors in [5] performed sizing relying on NASA's historical data (i.e., weather data and load profile), while the authors in [14] developed an EM strategy using data originating from the technical report of NREL (National Renewable Energy Laboratory). Several websites provide free historical weather data of many regions of the world as well as load profiles of different energy scales (home, residential/ commercial building, etc.).

5.2.2. Probabilistic Models. Probabilistic models assume that uncertain parameters such as demand load, wind speed, solar irradiation, and temperature follow a certain probability distribution function. From the selection, only one paper [43] used this type of models. The authors considered the speed of wind as a random variable following a Weibull distribution function with two parameters:

$$
F\left(V_{\text {wind }}\right)=\frac{\eta}{c} \times\left(\frac{V_{\text {wind }}}{c}\right)^{\eta-1} \times \exp \left(-\left(\frac{V_{\text {wind }}}{c}\right)^{\eta}\right)
$$

where $V_{\text {wind }}$ is the wind speed $(\mathrm{m} / \mathrm{s}), c$ is the scale factor of the Weibull distribution wind with unit of speed, and $\eta$ is the shape factor of the Weibull distribution, which is dimensionless. Different methods exist for the computation of these parameters, and the authors in [43] used the following two expressions:

$$
\begin{aligned}
& \eta={\frac{\sigma_{w}}{V_{\text {mean }}}}^{-1.086}, \\
& c=\frac{V_{\text {mean }}}{\gamma(1+(1 / \eta))},
\end{aligned}
$$

where the $\gamma$ is the gamma function, $V_{\text {mean }}$ is the average value of the wind speed data, and $\sigma_{w}$ is the standard deviation of the wind speed data. The accuracy of such models is verified through the comparison of their output with the existing actual data.

5.2.3. Forecasting Models. Forecasting is the process of estimating what will happen in the future based on the information possessed in the present and the past. It is a very useful method to handle the uncertainty issues within $\mu$ grid systems. Table 6 gives an overview of the different forecasting models that were employed by the selection.

The most chosen candidates for forecasting are Model Predictive Controller (MPC), Two-Point Estimate Method (TPEM), and Artificial Neural Networks (ANN). The MPC was used in $[6,15]$ to determine the optimal output regarding the objective function in a time control horizon of $12 \mathrm{~h}$ in [6] and $6 \mathrm{~h}$ in [15]. Aside from the data forecasting stage used in [15], another stage was added to adjust the errors made by the predictive model.

Uncertainties with the market price changes, the load demand forecast error, and the RER output power changes were handled by TPEM in [14]. The authors in [9] used the same method to forecast the RER output and to estimate the load demand.

In $[23,42]$, the authors chose the MLPNN to model the system uncertainties and predict the day-ahead values. The predictions of PV power, wind speed, and load demand are modelled using neural networks in [33]. The authors in [34] applied a heterogeneous ANN composed from an aggregation of MLPNN, radial basis function neural network (RBFNN), and recurrent neural network (RNN) to make an hour-ahead forecasting of load demand and wind power generation and a $24 \mathrm{~h}$ ahead forecasting of solar power generation.

Other methods were used in the selection. We cite

(i) General Collocated Velocity (GCV) solver [3] used to estimate the energy produced by wind farms

(ii) Lagrange duality method used in $[19,20]$ as a stochastic off-line approach with a $6 \mathrm{~h}$ control horizon, and an online deterministic approach was juxtaposed to the first stage with a $10 \mathrm{~min}$ time slot interval

(iii) Autoregressive Moving Average (ARMA) [36]

(iv) Fast Fourier transformation (FFT) [45]

5.2.4. Stochastic Optimization. This method optimizes an objective function of a system under specific uncertainties. The application of stochastic optimization for smart grid applications was thoroughly reviewed in [55]. From the 
TABLE 6: Algorithms for forecasting.

\begin{tabular}{lc}
\hline Ref. & Algorithm \\
\hline$[3]$ & GCV \\
{$[6,15]$} & MPC \\
{$[9,14]$} & TPEM \\
{$[19,20]$} & Lagrange duality method \\
{$[23,42]$} & MLPNN \\
{$[33,34]$} & ANN \\
{$[36]$} & ARMA \\
{$[45]$} & FFT \\
\hline
\end{tabular}

selection, only the authors of two works $[38,40]$ employed this method, and they both adopted the robust optimization and a branch of the former, optimizing the output of a system under the worst case scenario.

\subsection{Constraints}

5.3.1. Energy Balance. The main constraint to consider is delivering noninterrupted energy to the consumer. This constraint is considered in all papers. It allows to keep customer comfort at a certain level and avoid the energy shortage and possible outage risks. The general expression of this constraint that has to be fulfilled at each time step of the control horizon is

$$
\text { Load }- \text { Generation }=0 \text {, }
$$

where the first term refers to the consumed energy by the customer's appliances and the second term refers to the energy produces locally by the DER and RER. During its charging phase, the ESS is considered a load and a generation when discharging. In [15], the energy balance constraint was split into two separate balances: electrical and thermal balance. The thermal balance constraint is further split in [40] into cooling balance and heating balance. The mathematical expression of this constraint gets complicated when dealing with shifting strategies. In fact, additional parameters are involved such as the schedule of each appliance $i$ over the control horizon $T: x_{i}=\left(x_{i}\right)_{0<t \leq T}$, and the binary variable $u_{i}$ equal to 1 if the appliance is on, and 0 otherwise.

5.3.2. Power and Capacity of Components. The technical constraints of $\mu$ grid components are expressed by the limitations on their nominal power or capacity.

(1) Generation Units. The power generation of the DER units $P_{\mathrm{DER}}$ is limited by an upper limit $P_{\mathrm{DER}_{\max }}$ and a lower limit $P_{\mathrm{DER}_{\min }}[6,12,21,28,31,37]$.

In [38], the authors give a comprehensive set of constraints for DER concerning

(i) The initial on-line/off-line requirements for the generation units.

(ii) Minimum number of time periods the generator must remain on-line/off-line after the minimum off-line/on-line required time. (iii) Minimum number of time periods the generator must remain on-line/off-line at the end of the time horizon.

(iv) A generator can change its power supply depending on its ramping rate $\left.\left.r_{\mathrm{DER}} \in\right] 0,1\right]$, which determines how fast the generation can be changed hourly, or when the generator is turned on or off a similar constraint figures in [28, 40], see equation (21).

(v) Common constraints such as the lower and upper limits of each generator as well as start-up and shutdown costs' computation:

$$
\left|P_{\mathrm{DER}}(t)-P_{\mathrm{DER}}(t-1)\right|<r_{\mathrm{DER}} \cdot P_{\mathrm{DER}} .
$$

The capacity of the DER inverter $s_{\text {DER }}$ was considered in [28], and the constraint related to it limits the active power $p_{\mathrm{DER}}$ and the reactive power $q_{\mathrm{DER}}$ of the DER:

$$
p_{\mathrm{DER}}^{2}(t)+q_{\mathrm{DER}}^{2}(t) \leq s_{\mathrm{DER}}^{2} .
$$

In [25], the authors include an upper bound for the daily fuel consumption.

(2) Utility Grid Unit (for the on-Grid Mode). Some papers do not assign constraints on the utility grid, and this implies that the utility grid can provide the $\mu$ grid with any amount of energy it needs, and in case of a bidirectional flow of energy, the $\mu$ grid can inject all of its generation excess into the utility. Others, such as in $[16,21,27,31,40]$, limit the power exchanged with the utility $P_{\text {Grid }}$ by an upper limit $P_{\text {Grid }_{\max }}$ and a lower limit $P_{\text {Grid }_{\min }}$. The upper limit is constrained by an upper bound $P_{\text {peak }}$ in $[16,27,30]$. This last constraint is usually called the peak shaving constraint because it helps the network avoid overload events and reduces peak to average ratio (PAR). The term $P_{\text {Grid }_{\min }}$ limits the power to be injected into the grid: $P_{\text {injected }} \leq\left|P_{\text {Grid }_{\min }}\right|$

The authors in [38] have followed another policy: only the amount of energy exchanged under a firm contract is bounded, which means that the grid can exchange any amount with the $\mu$ grid but with different price rates. If the exchanged amount is under a certain upper limit, the energy will be exchanged at a price $F$ (Firm) and a price $N$ (nonFirm) otherwise.

(3) Load Unit. For papers working with a load management strategy, constraints on the loads are considered. In $[12,13,26,37]$, a minimum and a maximum power consumption of each appliance is determined. This constraint is further split into two constraints in [28]: a constraint on the active power of the appliance, and another one on the reactive power.

(4) Storage Units. When considering the storage, many constraints should be taken into account: the capacity constraint, the charging/discharging rate constraint, and the charging/discharging limits. Since the majority of papers implement an electrical storage, we will focus first on the constraints on this type of storage. A deep discharging or an extra charging can damage the ESS. Batteries, for instance, 
undergo a fast degradation if discharged under the optimal DoD. This constraint is expressed by the capacity of the ESS at a time $t C_{\min } \leq C(t) \leq C_{\max }$ or with the state of charge (SOC) of the ESS: $\mathrm{SOC}_{\min } \leq \mathrm{SOC}(t) \leq \mathrm{SOC}_{\max }$. SOC defines the percentage of the stored amount compared to the total capacity of an ESS: $\operatorname{SOC}(t)=C(t) / C_{\max }$. The charging (resp. discharging) rate is the rate at which a storage is charged (resp. discharged) relative to its capacity. The two parameters are bounded by an upper limit and a lower limit:

$$
\begin{gathered}
\beta_{\text {char }_{\text {min }}} \leq \beta_{\text {char }} \leq \beta_{\text {char }_{\text {max }},} \\
\beta_{\text {dis }_{\text {min }}} \leq \beta_{\text {dis }} \leq \beta_{\text {dis }_{\text {max }} .}
\end{gathered}
$$

To simplify, the charging rate is taken equal to the discharging rate. Additional constraints on the electrical storage include the following. The SOC at the end must be equal to the SOC at the beginning of the time horizon as in [26]. Constraint on the storage inverter in [28] is

$$
p_{b}^{2}(t)+q_{b}^{2}(t) \leq s_{b}^{2}
$$

where $s_{b}^{2}$ is the inverter's capacity and $p_{b}$ and $q_{b}$ are, respectively, the battery's active and reactive powers.

Constraints on the thermal storage are identical to the electrical storage: bounds on capacity and charging/discharging rates (Cf. [40]). A detailed series of constraint equations for the pump-storage system can be found in $[9,42]$.

5.3.3. Network Constraints. The network constraints frequently considered are the bus voltage limit, the bus frequency limit (for the AC configurations), the active/reactive power limits, the feeder limit, and the physical capacity of the transmission lines.

(1) Bus Voltage and Frequency Limits. The bus voltage $V$ should not exceed a voltage limit defined by the sum of the nominal voltage and a tolerance range (habitually $\left.V_{\text {nom }} \pm 5 \%[9,28]\right)$. In the expression below, the voltage is an absolute term and the two bounds are positives:

$$
V_{\min } \leq|V| \leq V_{\max }
$$

The same rule applies on the frequency [43]. The bus operation frequency should be maintained within a $0.5 \mathrm{~Hz}$ around the nominal frequency:

$$
f^{\min } \leq f \leq f^{\max }
$$

(2) Active/Reactive Power. In [9], the constraints on the active power $P$ and reactive power $Q$ are expressed by

$$
\begin{aligned}
P_{G, i}-P_{L, i} & =\sum_{j}\left|V_{i}\right|\left|V_{j}\right| Y_{i j} \cos \left(\theta_{i j}+\alpha_{j}-\alpha_{i}\right), \\
Q_{G, i}-Q_{L, i} & =\sum_{j}\left|V_{i}\right|\left|V_{j}\right| Y_{i j} \sin \left(\theta_{i j}+\alpha_{j}-\alpha_{i}\right),
\end{aligned}
$$

where $V_{i}$ and $V_{j}$ are the $i / j$-bus voltage, $\alpha_{j}$ and $\alpha_{i}$ are the voltage angle of bus $i$ and $j$ in rand, and $\theta_{i j}$ angle of complex $Y$-bus element.
(3) Feeder Flow Limit. The apparent power flow $S_{i j}$ from the bus $i$ to the bus $j$ in [9] was subject to a limit constraint:

$$
S_{i j} \leq S_{i j}^{\max } \text {. }
$$

(4) Physical Capacity of the Transmission Lines. These constraints were considered in [38]. In fact, each medium has a predefined capacity; transmitting a power flow higher than this capacity is called the thermal limit violation. Nevertheless, the voltage is the most important parameter of the transmission line since it gives an idea about the power that the line can hold. Therefore, if the voltage limit were respected, the capacity limitation is not considered.

5.3.4. User Comfort. For certain papers, the user comfort was included in the objective function as the cost of shifting appliances from the preferred period of operation. In other papers, the user comfort is expressed as a constraint.

In [8], three parameters were considered:

(i) Thermal comfort was measured using the thermal comfort index: predicted mean vote (PMV)

(ii) Visual comfort was measured by illuminance, which is an index for assessing the quantity of light

(iii) The priority comfort was measured using the priority list of the costumer

The user comfort constraint in [9] was expressed by the equation given below. $D_{f}$ and $D_{\text {init }}$ refer, respectively, to the demand load after DSM application and the initial demand load, $e$ is the elasticity coefficient and it translates the willingness of the consumer to shift their loads, and $\mathrm{Pr}_{0}$ is the base utility price:

$$
D_{f}=D_{\text {init }} \times\left[1+e\left(\frac{\text { Penality }- \text { Incentive }}{\operatorname{Pr}_{0}}\right)\right] .
$$

The load shifting was subject to the following constraint: $\left|D_{f}-D_{\text {init }}\right| \leq x_{\%} D_{\text {init }}$, where $x_{\%}$ is the percentage of shifting that the DSM algorithm must not exceed.

5.3.5. Budget Constraint. The budget is an important parameter to consider when searching for an optimal sizing of the $\mu$ grid. Unfortunately, only the authors in [26] have considered this condition and required that the sum of purchasing cost, installation cost, and O\&M costs of equipment should not exceed an upper bound.

5.3.6. Renewable Factor. The authors in paper [1] consider the renewable factor as the quantity of power generated from the diesel generator compared to the amount generated from RERs:

$$
\mathrm{RF}=100 \times\left(1-\frac{P_{\mathrm{DG}}}{P_{\mathrm{RER}}}\right) .
$$

The more RF approaches $100 \%$, the more it is efficient because it means that the system covers its energy need 


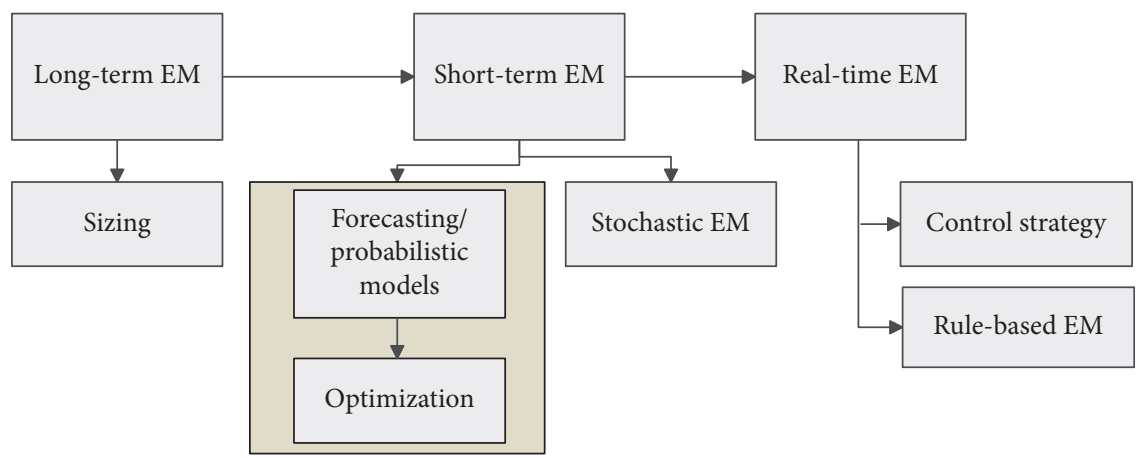

Figure 8: The proposed EM strategy.

mainly from RERs. While, in [5], the authors used a more generic expression. RF refers to the energy delivered to the load by RERs compared to non-RERs:

$$
\mathrm{RF}=100 \times\left(1-\frac{P_{\text {non-RER }}}{P_{\text {Load }}}\right) .
$$

5.3.7. Islanding Constraint. In [30], the authors adapted the on/off $\mu$ grid mode of operation. In case of a shortage event when the $\mu$ grid has to switch between on-to offmode, a minimum energy level for the total storage in the network is computed adaptively to ensure sufficient energy reserve.

\section{Study Limitations}

The first limitation that we had to face was the huge number of papers that cover the EM topic. The study would have been more interesting if we had covered all the papers from the selection process. Yet, due to their massive number, we were obliged to restrict our study to the 15 first relevant papers of each database. This restriction has the drawback of leaving behind papers that suggest worthwhile methods and strategies. After the selection was done and during the extraction process, we encountered a lack of information. In fact, important information was missing in some papers such as the adopted utility price policy or the type of batteries. A lot of papers did not mention the complexity of their suggested algorithms. Thus, we were not able to perform a quality assessment and apply a comparative study of the suggested algorithms.

\section{Conclusion and Suggestions}

Managing the energy usage in $\mu$ grids has a vast impact in energy efficiency and sustainability research. This SLR proposes an overlook on different EM strategies suggested by researchers for green $\mu$ grid systems. It starts by summarizing the different architectures proposed in the literature. This includes the components that compose a $\mu$ grid, the different operation modes, and a brief discussion on the energy exchange policy with the main grid network. Then, the review proceeds to presenting the various methods, algorithms, and tools that help perform EM and concludes with pointing out objectives and faced constraints.

As a result of this SLR, we propose a methodology for an efficient use of energy in a green $\mu$ grid system. As shown in Figure 8, a good EM starts with a sizing study. The sizing will have the benefit of increasing the ROI in a long-term vision and help decrease the energy waste due to the frequent overgeneration. To perform the sizing, rule-based strategies and linear programming are the most appropriate for the task. The short term EM is a critical block since it is where the unpredictable behaviour of RERs is handled. It is usually performed in a daily basis and can be done in two different ways: utilize the stochastic optimization or combine a two-block strategy that includes a forecasting block and deterministic optimization block. The last part of the methodology is processed real time. It is generally a rule-based strategy. This part has the task of compensating the differences between the scheduled values and the actual values. The correction and the regulation of the system's electric signals are performed at this level as well.

A significant part that starts to emerge and that was not detailed in this paper regards the cooperative energy management strategies. In fact, by allowing $\mu$ grids to collaborate, the costs resulting from losses can be significantly reduced, especially with the integration of an efficient distributed EM strategy. The peer-to-peer interconnection of numerous $\mu$ grids in a distribution network will take us one step towards the future smart grid network. Therefore, it is essential to take into account the cooperative aspect in each step of the suggested methodology.

We have to bear in mind that EM strategies reviewed here are highly related to the communication infrastructure. In fact, in all EM Strategies, we assume that the EMS receives all the information it requires. Yet, we have to consider whether this is feasible or not. The communication architecture carrying the $\mu$ grid information is made of small-capacity sensors and channels that are not very robust. Transmitting massive data on a real-time basis for the EM purpose is questionable.

\section{Conflicts of Interest}

The authors declare that they have no conflicts of interest. 


\section{References}

[1] M. A. M. Ramli, H. R. E. H. Bouchekara, and A. S. Alghamdi, "Optimal sizing of PV/wind/diesel hybrid microgrid system using multi-objective self-adaptive differential evolution algorithm," Renewable Energy, vol. 121, pp. 400-411, 2018.

[2] Z. Wang, C. Gu, and F. Li, "Flexible operation of shared energy storage at households to facilitate PV penetration," Renewable Energy, vol. 116, pp. 438-446, 2018.

[3] S. Proietti, P. Sdringola, F. Castellani, D. Astolfi, and E. Vuillermoz, "On the contribution of renewable energies for feeding a high altitude smart mini grid," Applied Energy, vol. 185, pp. 1694-1701, 2017.

[4] P. Couty, M. J. Lalou, C. Peter, S. Cotture, and V. Saade, "Positive energy building with PV facade production and electrical storage designed by the swiss team for the U.S. Department of Energy Solar Decathlon 2017," Energy Procedia, vol. 122, pp. 919-924, 2017.

[5] L. M. Halabi and S. Mekhilef, "Flexible hybrid renewable energy system design for a typical remote village located in tropical climate," Journal of Cleaner Production, vol. 177, pp. 908-924, 2018.

[6] D. Morin, Y. Stevenin, C. Grolleau, and P. Brault, "Evaluation of performance improvement by model predictive control in a renewable energy system with hydrogen storage," International Journal of Hydrogen Energy, vol. 43, no. 45, pp. 21017-21029, 2018.

[7] N. T. Mbungu, R. C. Bansal, R. Naidoo, V. Miranda, and M. Bipath, "An optimal energy management system for a commercial building with renewable energy generation under real-time electricity prices," Sustainable Cities and Society, vol. 41, pp. 392-404, 2018.

[8] F. Sehar, M. Pipattanasomporn, and S. Rahman, “An energy management model to study energy and peak power savings from PV and storage in demand responsive buildings," Applied Energy, vol. 173, pp. 406-417, 2016.

[9] G. Ahmad and M. Enayatzare, "Optimal energy management of a renewable-based isolated microgrid with pumped-storage unit and demand response," Renewable Energy, vol. 123, pp. $460-474,2018$.

[10] V. Kamala Devi, K. Premkumar, and A. Bisharathu Beevi, "Energy management using battery intervention power supply integrated with single phase solar roof top installations," Energy, vol. 163, pp. 229-244, 2018.

[11] A. Chauhan and R. P. Saini, "Techno-economic optimization based approach for energy management of a stand-alone integrated renewable energy system for remote areas of India," Energy, vol. 94, pp. 138-156, 2016.

[12] R. Rahmani, I. Moser, and M. Seyedmahmoudian, "Multiagent based operational cost and inconvenience optimization of PV-based microgrid," Solar Energy, vol. 150, pp. 177-191, 2017.

[13] G. Prinsloo, A. Mammoli, and R. Dobson, "Discrete cogeneration optimization with storage capacity decision support for dynamic hybrid solar combined heat and power systems in isolated rural villages," Energy, vol. 116, pp. 1051-1064, 2016.

[14] F. Najibi, T. Niknam, and A. Kavousi-Fard, "Optimal stochastic management of renewable mg (micro-grids) considering electro-thermal model of PV (photovoltaic)," Energy, vol. 97, pp. 444-459, 2016.

[15] T. M. Kneiske, M. Braun, and D. I. Hidalgo-Rodriguez, "A new combined control algorithm for PV-CHP hybrid systems," Applied Energy, vol. 210, pp. 964-973, 2018.
[16] L. N. An, T. T. Minh Dung, and T. Quoc-Tuan, "Optimal energy management for an on-grid microgrid by using branch and bound method," in Proceedings of the 2018 IEEE International Conference on Environment and Electrical Engineering and 2018 IEEE Industrial and Commercial Power Systems Europe (EEEIC/I CPS Europe), pp. 1-5, Palermo, Italy, June 2018.

[17] C. Keles, A. Kaygusuz, and B. B. Alagoz, "Multi-source energy mixing by time rate multiple PWM for microgrids," in Proceedings of the 2016 4th International Istanbul Smart Grid Congress and Fair (ICSG), pp. 1-5, Istanbul, Turkey, April 2016.

[18] C. Keles, B. B. Alagoz, and A. Kaygusuz, "Multi-source energy mixing for renewable energy microgrids by particle swarm optimization," in Proceedings of the 2017 International Artificial Intelligence and Data Processing Symposium (IDAP), Malatya, Turkey, September 2017.

[19] K. Rahbar, J. Xu, and R. Zhang, "Real-time energy storage management for renewable integration in microgrid: an offline optimization approach," IEEE Transactions on Smart Grid, vol. 6, no. 1, pp. 124-134, 2015.

[20] K. Rahbar, C. C. Chai, and R. Zhang, "Energy cooperation optimization in microgrids with renewable energy integration," IEEE Transactions on Smart Grid, vol. 9, no. 2, pp. 1482-1493, 2018.

[21] A. T. Eseye, D. Zheng, and J. Zhang, "Optimal energy management strategy for an isolated industrial microgrid using a modified particle swarm optimization," in Proceedings of the 2016 IEEE International Conference on Power and Renewable Energy (ICPRE), pp. 494-498, Vienna, Austria, October 2016.

[22] W. Huang, Z. Fu, and L. Hua, "Research on optimal capacity configuration for distributed generation of island micro-grid with wind/solar/battery/diesel engine," in Proceedings of the 2018 2nd IEEE Conference on Energy Internet and Energy System Integration (EI2), pp. 1-6, Beijing, China, October 2018.

[23] U. B. Tayab, F. Yang, M. El-Hendawi, and J. Lu, "Energy management system for a grid-connected microgrid with photovoltaic and battery energy storage system," in Proceedings of the 2018 Australian New Zealand Control Conference (ANZCC), pp. 141-144, Melbourne, Australia, December 2018.

[24] M. H. F. Ahamed, U. D. S. D. Dissanayake, H. M. P. De Silva, H. R. C. G. P. Pradeep, and N. W. A. Lidula, "Modelling and simulation of a solar PV and battery based DC microgrid system," in Proceedings of the 2016 International Conference on Electrical, Electronics, and Optimization Techniques (ICEEOT), pp. 1706-1711, Chennai, India, March 2016.

[25] S. R. Alvarez, A. M. Ruiz, and J. E. Oviedo, "Optimal design of a diesel-PV-wind system with batteries and hydro pumped storage in a colombian community," in Proceedings of the 2017 IEEE 6th International Conference on Renewable Energy Research and Applications (ICRERA), pp. 234-239, San Diego, CA, USA, November 2017.

[26] H. Wang and J. Huang, "Joint investment and operation of microgrid," IEEE Transactions on Smart Grid, vol. 8, no. 2, pp. 833-845, 2017.

[27] L. An and T. Quoc-Tuan, "Optimal energy management for grid connected microgrid by using dynamic programming method," in Proceedings of the 2015 IEEE Power Energy Society General Meeting, pp. 1-5, Denver, CO, USA, July 2015. 
[28] W. Shi, X. Xie, C.-C. Chu, and R. Gadh, "Distributed optimal energy management in microgrids," IEEE Transactions on Smart Grid, vol. 6, no. 3, pp. 1137-1146, 2015.

[29] R. S. Karki and S. Chanana, "Simulation of energy management system for local energy market in microgrids," in Proceedings of the 2016 IEEE Students' Conference on Electrical, Electronics and Computer Science (SCEECS), pp. 1-6, Bhopal, India, March 2016.

[30] M. R. Sandgani and S. Sirouspour, "Coordinated optimal dispatch of energy storage in a network of grid-connected microgrids," IEEE Transactions on Sustainable Energy, vol. 8, no. 3, pp. 1166-1176, 2017.

[31] L. Han, A. T. Eseye, J. Zhang, and D. Zheng, "Optimal energy management for industrial microgrids with high-penetration renewables," Protection and Control of Modern Power Systems, vol. 2, no. 1, p. 12, 2017.

[32] I. Fatima, A. Khalid, S. Zahoor et al., "Home energy management system using ant colony optimization technique in microgrid," in Advances on Broad-Band Wireless Computing, Communication and Applications, B. Leonard, F. Xhafa, and Jordi Conesa, Eds., Springer International Publishing, Cham, Switzerland, 2018.

[33] E. Cruz May, L. J. Ricalde, E. J. R. Atoche, A. Bassam, and E. N. Sanchez, "Forecast and energy management of a microgrid with renewable energy sources using artificial intelligence," in Intelligent Computing Systems, C. Brito-Loeza and A. Espinosa-Romero, Eds., Springer International Publishing, Cham, Switzerland, 2018.

[34] P. G. Harhammer and A. Schadler, "Optimal energy management," in System Modelling and Optimization, A. Prékopa, J. Szelezsáan, and B. Strazicky, Eds., Springer Berlin Heidelberg, Berlin, Heidelberg, Germany, 1986.

[35] L. Raju, A. A. Morais, and R. S. Milton, "Advanced energy management of a micro-grid using Arduino and multi-agent system," in Intelligent and Efficient Electrical Systems, M.C. Bhuvaneswari and J. Saxena, Eds., Springer, Singapore, 2018.

[36] T. Bogaraj and J. Kanakaraj, "Intelligent energy management control for independent microgrid," Sādhanā, vol. 41, pp. 755-769, 2016.

[37] S. Ghorbani, R. Rahmani, and R. Unland, "Multi-agent autonomous decision making in smart micro-grids' energy management: a decentralized approach," in Multiagent System Technologies, J. O. Berndt, P. Petta, and R. Unland, Eds., Springer International Publishing, Cham, Switzerland, 2017.

[38] J. L. Ruiz Duarte and N. Fan, "Operations of a microgrid with renewable energy integration and line switching," Energy Systems, vol. 10, no. 3, 2018.

[39] R. Jansen and R. Karki, Sustainable Energy Optimization in a Smart Microgrid, Springer, Singapore, 2017.

[40] Z. Luo, W. Gu, Z. Wu, Z. Wang, and Y. Tang, "A robust optimization method for energy management of CCHP microgrid," Journal of Modern Power Systems and Clean Energy, vol. 6, no. 1, pp. 132-144, 2018.

[41] G. Aghajani and N. Yousefi, "Multi-objective optimal operation in a micro-grid considering economic and environmental goals," Evolving Systems, vol. 10, no. 7, 2018.

[42] H. Shayeghi and E. Shahryari, Integration and Management Technique of Renewable Energy Resources in Microgrid, Springer International Publishing, Cham, Switzerland, 2017.

[43] T. Madiba, R. C. Bansal, J. J. Justo, and K. Kusakana, Optimal Control System of under Frequency Load Shedding in Microgrid System with Renewable Energy Resources, Springer International Publishing, Cham, Switzerland, 2017.
[44] J. Klaimi, R. Rahim-Amoud, and L. Merghem-Boulahia, Energy Management in the Smart Grids via Intelligent Storage Systems, Springer International Publishing, Cham, Switzerland, 2017.

[45] T. Brandt, Designing an Energy Information System for Microgrid Operation, Springer, Wiesbaden, Germany, 2016.

[46] A. Awasthi, V. Karthikeyan, V. Das, S. Rajasekar, and A. K. Singh, Energy Storage Systems in Solar-Wind Hybrid Renewable Systems, Springer International Publishing, Cham, Switzerland, 2017.

[47] Energyplus Web-Based Documentation, 2015, https://biglad dersoftware.com/epx/docs/8-0/engineering-reference/page-076. html.

[48] G. Dutta and K. Mitra, "A literature review on dynamic pricing of electricity," Journal of the Operational Research Society, vol. 68, no. 10, pp. 1131-1145, 2017.

[49] M. M. D. Ross, D. Turcotte, and S. Roussin, "Comparison of $\mathrm{AC}, \mathrm{DC}$, and AC/DC bus configurations for PV hybrid systems," Report Submitted to CETC-Varennes in Fulfillment of Contract, 2005.

[50] J. S. del Moral and M. Á. Egido, Simulation of AC, DC, and AC-DC Coupled Mini-Grids in Search of the Most Efficient System, Universidad Politécnica de Madrid, Madrid, Spain, 2012.

[51] M. Ourahou, W. Ayrir, B. El Hassouni, and A. Haddi, "Review on smart grid control and reliability in presence of renewable energies: challenges and prospects," Mathematics and Computers in Simulation, vol. 167, pp. 19-31, 2018.

[52] P. G. Arul, V. K. Ramachandaramurthy, and R. K. Rajkumar, "Control strategies for a hybrid renewable energy system: a review," Renewable and Sustainable Energy Reviews, vol. 42, pp. 597-608, 2015.

[53] M. Faccio, M. Gamberi, M. Bortolini, and M. Nedaei, "Stateof-art review of the optimization methods to design the configuration of Hybrid Renewable Energy Systems (HRESS)," Frontiers in Energy, vol. 12, no. 4, pp. 591-622, 2018.

[54] T. Weise, Global Optimization Algorithms-Theory and Application, Institute of Applied Optimization, Hefei University, Hefei, China, 2009.

[55] S. S. Reddy, V. Sandeep, and C.-M. Jung, "Review of stochastic optimization methods for smart grid," Frontiers in Energy, vol. 11, no. 2, pp. 197-209, 2017. 